\section{1}

\title{
Longitudinal Auditory Pathophysiology Following Mild Blast Induced Trauma
}

Emily X. Han ${ }^{1,2}$, Joseph M. Fernandez ${ }^{2,3}$, Caitlin Swanberg ${ }^{2}$, Riyi Shi ${ }^{2,3}$, Edward L. Bartlett $^{1,2}$ ${ }^{1}$ Dept. of Biological Sciences, College of Science, Purdue University, West Lafayette, IN

${ }^{2}$ Weldon School of Biomedical Engineering, Purdue University, West Lafayette, IN

${ }^{3}$ Dept. Basic Medical Sciences, College of Veterinary Medicine, Purdue University, West Lafayette, IN

Running head: Longitudinal blast auditory pathophysiology Correspondence should be addressed to Edward Bartlett (ebartle@purdue.edu)。 Department of Biological Sciences and The Weldon School of Biomedical Engineering 206 S. Martin Jischke Dr. Purdue University West Lafayette, Indiana 47907-1791 
bioRxiv preprint doi: https://doi.org/10.1101/2020.11.06.371591; this version posted July 18, 2021. The copyright holder for this preprint (which was not certified by peer review) is the author/funder, who has granted bioRxiv a license to display the preprint in perpetuity. It is made available under aCC-BY-NC-ND 4.0 International license. 


\section{Abstract}

Blast-induced hearing difficulties affect thousands of veterans and civilians. The long-term impact of even a mild blast exposure on the central auditory system is hypothesized to contribute to lasting behavioral complaints associated with mild blast traumatic brain injury (bTBI). Although recovery from mild blast has been studied separately over brief or long time windows, few, if any, studies have investigated recovery longitudinally over short-term and longer-term (months) time windows. Specifically, many peripheral measures of auditory function either recover or exhibit subclinical deficits, masking deficits in processing complex, real-world stimuli that may recover differently. Thus, examining the acute time course and pattern of neurophysiological impairment using appropriate stimuli is critical to better understanding and intervention of bTBI-induced auditory system impairments. Here, we compared auditory brainstem response, middle-latency auditory evoked potentials, and envelope following responses. Stimuli were clicks, tone pips, amplitude modulated tones in quiet and in noise, and speech-like stimuli (iterated rippled noise pitch contours) in adult male rats subjected to mild blast and sham exposure over the course of two months. We found that blast animals demonstrated drastic threshold increases and auditory transmission deficits immediately after blast exposure, followed by substantial recovery during the window of 7-14 days post-blast, though with some deficits remaining even after two months. Challenging conditions and speech-like stimuli can better elucidate mild bTBI-induced auditory deficit during this period. Our results suggest multiphasic recovery and therefore 
potentially different time windows for treatment, and deficits can be best observed using a small battery of sound stimuli.

48

\section{New and Noteworthy}

$50 \quad$ Few studies on blast-induced hearing deficits go beyond simple sounds and sparsely

51 track post-exposure. Therefore, the recovery arc for potential therapies and

52 real-world listening is poorly understood. Evidence suggested multiple recovery

53 phases over 2 months post-exposure. Hearing thresholds largely recovered within

5414 days and partially explained recovery. However, mid-latency responses,

55 responses to $\mathrm{AM}$ in noise, and speech-like pitch sweeps exhibited extended

56 changes, implying persistent central auditory deficits and the importance of

57 subclinical threshold shifts. 
Hearing loss stands out as one of the most commonly reported consequences

following blast injuries and can last for months or even years without significant external injury (Cohen et al. 2002; Cave et al. 2007; Ritenour et al. 2008; Saunders et al. 2015). Most studies regarding blast-induced hearing loss have focused on damage in different parts of the peripheral auditory system (PAS) (Kerr 1980; DePalma et al. 2005), including hair cells, cochlear synapses, and auditory nerve damage. However, significant hearing difficulties can occur in the absence of peripheral diagnostic indicators such as eardrum rupture or clinical threshold shifts (hearing loss $>25 \mathrm{~dB}$ ), indicating potential disruptions upstream (Remenschneider et al. 2014; Saunders et al. 2015; Van Haesendonck et al. 2018). Increasing clinical (Berger et al. 1997; Cohen et al. 2002; Cave et al. 2007; Ritenour et al. 2008; Lew et al. 2009; Gallun et al. 2012a) and laboratory (Patterson and Hamernik 1997; Ewert et al. 2012; Cho et al. 2013b; Du et al. 2013; Masri et al. 2018) findings suggest that the central auditory system (CAS) contains blast-susceptible structures. Subcortical CAS may be particularly vulnerable to blast injury, including mechanical damage and blood-brain barrier (BBB) permeability, excitotoxicity, and elevated markers of oxidative stress and neuroinflammation for at least 2 weeks (Knudsen and Øen 2003; Leung et al. 2008; Säljö et al. 2011; Cho et al. 2013a; Song et al. 2015; Walls et al. 2016). Functional changes, such as hyperactivity in the auditory brainstem (Luo et al. 2014a, 2014b) or structural changes in OHC loss 
2012), have been shown at 1-2 time points post-blast at various time points up to 2-3 weeks. Understanding the trajectory of post-blast recovery from primary and secondary damage can help to identify critical time points for diagnostics and therapies.

Clinical reports have suspected "hidden hearing loss" in blast-exposed veterans due to deficits in suprathreshold auditory processing with minimal changes in auditory thresholds (Gallun et al. 2012a; Saunders et al. 2015; Bressler et al. 2017) One consequence to this loss could be CAS adaptations to peripheral deafferentation (Caspary et al. 2005, 2008; Wang et al. 2009), which may lead to impaired temporal processing (Walton 2010; Parthasarathy and Bartlett 2011, 2012; Rabang et al. 2012). Blast studies on human subjects often used speech and complex temporally modulated stimuli to pin down "hidden" temporal processing losses at suprathreshold levels (Gallun et al. 2012b; Saunders et al. 2015; Bressler et al. 2017; Kubli et al. 2018). However, blast studies in animals rarely go beyond simple auditory stimuli (Ewert et al. 2012; Race et al. 2017; Masri et al. 2018).

In the current study, in addition to traditional measures, we chose Iterated Rippled Noise (IRN) to create a pitch contour with adjustable salience alongside Amplitude Modulation (AM) stimuli in quiet and in modulated noise as temporally complex stimuli in assessing the processing of temporal attributes. IRN has been used in neurophysiological and behavioral studies in both human (Krishnan et al. 2014, 2015;

Peter et al. 2014; Thompson and Marozeau 2014; Wagner et al. 2017) and animal 
102 models (Bendor and Wang 2005; Alsindi et al. 2018).

\section{Materials and Methods}

105

106

107

108 2016; Race et al. 2017).

\section{Subject} \#1111000280).

\section{Blast Exposure}

Male Sprague-Dawley rats (3-4 months) were assigned into Sham group and Blast group randomly. A total of 11 Sham animals and 13 blast animals were used in this study. For a given sound stimulus, only complete sets of responses that included all time points were used for analysis. In a few sessions, there were recording sessions contaminated by movement artifact or movements that displaced electrode positions, and response sets affected by those were not included. All animals were kept and raised in relatively quiet and standard laboratory animal housing conditions. All protocols were approved by the Purdue Animals Care and Use Committee (PACUC

Animals were anesthetized through intraperitoneal injection of a ketamine/xylazine cocktail (80 mg/kg and $10 \mathrm{mg} / \mathrm{kg}$, respectively). The absence of eye-blink and paw-withdrawal reflexes was ensured prior to proceeding. Anesthetized animals were then placed on a platform beneath an open-ended shock tube to be exposed to the blast event, as described in our prior publications (Song et al. 2015; Walls et al. 
124 For the Blast group, each rat's head was positioned beneath the open end of the

125 shock tube such that the dorsum of the skull was the incident surface exposed to a

126 composite blast (shock wave + blast wind). A custom plexiglass housing was

127 temporarily placed over the animal's torso for body protection to avoid cardiac or

128 pulmonary effects of blast and to simulate the protective effects of military body

129 armor (Rafaels et al. 2011). The head was fixed with a stereotaxic head frame with

130 bite bar and ear bars (Kopf Instruments) to prevent blast wind-induced head

131 acceleration. The blast exposure exhibited a recorded pressure profile with a rise to

132 peak pressure within $0.3 \mathrm{msec}$, followed by overpressure and underpressure periods

133 as follows: side-on (static) $150 \mathrm{kPa}$ maximum overpressure, $1.25 \mathrm{msec}$ overpressure

134 duration, and $20 \mathrm{kPa}$ minimum underpressure; face on (dynamic) $160 \mathrm{kPa}$ maximum

135 overpressure, 1.75 msec overpressure duration, and $5 \mathrm{kPa}$ minimum underpressure.

136 These conditions were the same as reported in our prior publications (Song et al.

137 2015; Walls et al. 2016; Race et al. 2017) and are considered to be a mild blast

138 exposure, given the magnitude of the exposure and its single occurrence. All but one

139 blast animal survived the exposure without displaying any motor or behavioral deficit

140 during each animal's longitudinal follow-up period.

142 Sham animals were placed equidistant from the blast source, but out of the path of

143 the shockwave, therefore only exposed to the blast noise. Tympanic membrane

144 integrity was verified for all Blast and Sham animals after injury using a surgical

145 microscope. 
(Insert Fig. 1 about here)

\section{Auditory Evoked Potential Recordings}

The animals underwent two-channel Auditory Evoked Potential (AEP) recordings at the following time points: pre-exposure (baseline), 1 day, 4 days, 7 days, 10 days, 14 days, 1 month, and 2 months. While the animals were under $1.8-2 \%$ isoflurane anesthesia, subdermal needle electrodes (Ambu) were inserted in the following locations (Fig. 1A): Channel 1 positive electrode was placed along the midline of the head (mid-sagittal) oriented $\mathrm{Fz}$ to $\mathrm{Cz}$. Channel 2 positive electrode was positioned positive electrodes for both channels 1 and 2) was placed under the mastoid of the right ear ipsilateral to the speaker. A ground electrode was placed in the back of the animal. These configurations were consistent with prior publications from our laboratory (Parthasarathy and Bartlett 2011, 2012; Parthasarathy et al. 2014; Lai and Bartlett 2015; Lai et al. 2017). Electrode impedances were confirmed to be less than $1 \mathrm{k} \Omega$ using a low impedance amplifier (RA4LI, TDT). After electrode placement, we subsequently sedated the animals by intramuscular injection of $0.2-0.3 \mathrm{mg} / \mathrm{kg}$ dexmedetomidine (Dexdomitor). AEP recordings were performed 10-15 min after removal from isoflurane to avoid anesthetic effects. The animals could respond to pain and acoustic stimuli but tend sit calmly under dexmedetomidine sedation, allowing about 3 hours of recording time. 
Acoustic stimuli were presented free-field to the right ear (90 $\square$ azimuth) of animals, with directly in front of the animals' face as the reference for $0 \square$ azimuth, using a calibrated speaker (Bowers and Wilkins) at a distance of $115 \mathrm{~cm}$ directly facing the right ear. The measurements used in this study included auditory brainstem responses (ABRs), middle-latency responses (MLRs), envelop-following responses (EFRs) using AM in noise stimuli, and IRNs.

\section{ABR and MLR}

6 Sham animals and 10 Blast animals were used in ABR analysis. For ABR, rectangular clicks ( $0.1 \mathrm{msec}$ duration) and tone-pips ( $2 \mathrm{msec}$ duration, $0.5 \mathrm{msec} \cos ^{2}$ rise-fall time) with frequencies of $8 \mathrm{kHz}$ and $16 \mathrm{kHz}$ were used. $8 \mathrm{kHz}$ and $16 \mathrm{kHz}$ were chosen based on previous findings: with $6-16 \mathrm{kHz}$ being the most sensitive hearing region of rats, $8 \mathrm{kHz}$ near the most sensitive region of normal rat audiogram (Parthasarathy et al. 2014) and hearing of frequencies higher than $8 \mathrm{kHz}$ being most vulnerable to blast injury (Race et al. 2017). The sound levels of clicks and pips ranged from 90 to $10 \mathrm{~dB}$ peak SPL in 5-dB steps. All stimuli were presented in alternating polarity at 26.6 per second with 1500 repetitions (750 at each polarity). A 20 msec acquisition window (0-20 msec) was used.

Data were processed with a $30 \mathrm{~Hz}$ high-pass (HP) filter and a $3000 \mathrm{~Hz}$ low-pass (LP) filter prior to analysis. The ABR threshold was visually determined as the minimum sound level that produced a distinct $A B R$ waveform, with confirmation from two other researchers. The ABR amplitudes of waves I and V from channel 2 were estimated 
as the differences of each wave's amplitude, as seen in BioSigRP (TDT) and the baseline amplitude (measured as an average of $2 \mathrm{msec}$ waveform prior to the cochlear microphonic).

6 Sham animals and 8 Blast animals were used in MLR analysis. For MLR, similar rectangular clicks and $8 \mathrm{kHz}$ tone pips of alternating polarity as in $\mathrm{ABR}$ were used but were presented at a slower rate (3.33/sec vs. $26.6 / \mathrm{sec}$ in $\mathrm{ABRs}$ ) and with a recording window of longer duration (100 msec vs. $20 \mathrm{msec}$ in ABRs). This time window provides enough time to capture the stimulus-evoked "middle-latency" neural responses from the auditory midbrain, thalamus and cortex (Barth and Shi Di 1991; McGee et al. 1991; Di and Barth 1992; McGee and Kraus 1996; Phillips et al. 2011; Šuta et al. 2011) alongside ABR. Stimuli were presented at $80 \mathrm{~dB}$ sound pressure level (SPL) and $30 \mathrm{~dB}$ sensation level (SL, $30 \mathrm{~dB}$ above corresponding ABR thresholds), as determined in the previous ABR recordings. 1500 repetitions were collected over an acquisition time window of $100 \mathrm{msec}$ to obtain an average response. Only one animal exhibited hearing threshold higher than $80 \mathrm{~dB} S P L$ at only one time point, for which MLR recording has been excluded for that point.

Channel 2 was used for MLR analyses, and results were qualitatively similar for channel 1. Data were processed with HP (fc $=10 \mathrm{~Hz}$ ) and LP (fc $=300 \mathrm{~Hz})$ filters prior to analysis.

\section{EFRs}


212 EFRs were recorded during the same recording session following ABRs and MLRs

213 using the same electrode configurations with similar techniques to Lai and Bartlett

214 (2018) and Lai (Lai et al. 2017). The two channels were sensitive to a

215 complementary range of amplitude modulation frequencies (AMFs) (Parthasarathy

216 and Bartlett 2012), with channel 1 (mid-sagittal) being more sensitive to higher AMFs

$217(90-2048 \mathrm{~Hz})$ while channel 2 (interaural) is more sensitive to lower AMFs $(8-90 \mathrm{~Hz})$.

218 The AM stimuli used for EFRs were sinusoidally amplitude-modulated (AM) sounds,

219 with Gaussian noise, $8 \mathrm{kHz}$ tone, or $16 \mathrm{kHz}$ tone as carriers, and under $100 \%$ and $50 \%$

220 modulation depth with a stimulus duration of $200 \mathrm{msec}$. The AMFs selected for this

221 study are $10 \mathrm{~Hz}, 45 \mathrm{~Hz}$, and $256 \mathrm{~Hz}$, based on the findings in Race at al. (Race et al.

222 2017), which found significant differences, particularly at the lower AMFs. The

223 acquisition window was $300 \mathrm{msec}$ long, and each response was an average of 200

224 repetitions. The stimuli were presented at $30 \mathrm{~dB}$ SL. For animals that had a hearing

225 threshold above $70 \mathrm{~dB}$ SPL, which usually happens on day 1 post-exposure, EFR

226 was not collected at the time point due to the limitation of the speaker and BiosigRP.

228 For AM in Noise stimuli, the same EFRs were used alongside a $71 \mathrm{~Hz}$ sinusoidally

229 AM masker of the same length and onset, with Gaussian noise as the carrier, similar

230 to Lai and Bartlett (Lai and Bartlett 2018). Noise AM maskers were presented at

231 sound levels of $20 \mathrm{~dB}$ SNR and OSNR to the sound level of target AM. Prior to EFR

232 amplitude analysis, data were passed through an LP filter of $3000 \mathrm{~Hz}$ and a

233 high-pass filter that was either slightly below the AMF for AMFs $<90 \mathrm{~Hz}$, or $80 \mathrm{~Hz}$ for 
IRN iteration (ite) stimuli were created with the same polynomial equations used for 255

$A M F s \geq 90 \mathrm{~Hz}$

\section{IRNs}

For 6 Sham animals and 8 Blast animals, IRNs were recorded during the same recording session following the previous stimuli using the same electrode configurations. The sound level of presentation was $30 \mathrm{~dB}$ SL (above click hearing threshold). Data for animals with a hearing threshold above $70 \mathrm{~dB}$ SPL were not collected at the time point.

IRN tone stimuli were created by sequential delay and add operations. Time-varying pitch curves were created by applying polynomial equations to create delays constructed from the fundamental frequencies of Chinese tone 2 and tone 4 , delaying Gaussian noise $(80 \mathrm{~Hz}-40 \mathrm{kHz}$ ) by the inversion of pitch and adding it back on itself in a recursive manner (Yost 1996a). The core MATLAB program used for generating IRN was modified from Krishnan et al. (Krishnan et al. 2014, 2015) This would generate dynamic, curvilinear pitch patterns (Swaminathan et al. 2008) that preserves variations in pitch using a broadband carrier. The number of iteration steps for these stimuli was 32 , beyond which there is little or no change in pitch salience (Yost 1996b).

tone 2, but with different iterations to create an array of IRN stimuli with different pitch 
256 salience. The numbers of iteration steps were $32,16,8,4$, and 2.

257 All IRN stimuli consisted of pairs of waveforms in original and inversed polarities to

258 compensate for envelope or fine structure response under different calculations and

259 cancel any microphonics. The stimulus duration was $250 \mathrm{msec}$, and the acquisition

260 window was 300 msec long. Each response was an average of 200 repetitions.

261 Given the main frequencies involved in the IRN autocorrelation $(>100 \mathrm{~Hz})$, channel 1

262 was used for IRN analyses, and results were qualitatively similar for channel 2.

\section{Statistics}

265 Statistics were performed with statistics software JASP (Version 0.11, JASP Team, 266 2019). All statistics for ABR and EFR utilized 2-way repeated measures ANOVA test

$267(\alpha=0.05)$ to check the significance of each main effect and interaction, undergoing

268 Greenhouse-Geisser sphericity corrections (Greenhouse and Geisser 1959) and

269 Tukey Post Hoc corrections (Tukey 1949). For ABR statistics, Wave I (channel 2), III

270 (channel 1) and $V$ (channel 2) were measured at each time point (Fig. 1B),

271 corresponding to the auditory nerve (Wave I), cochlear nucleus (Wave III), and

272 rostral brainstem/IC sources (Wave V) (Parthasarathy and Bartlett 2012; Simpson

273 and Prendergast 2013). For EFR statistics, responses were analyzed from channel 2

274 for $10 \mathrm{~Hz}$ and $45 \mathrm{~Hz}$, and from channel 1 for $256 \mathrm{~Hz}$ (Parthasarathy and Bartlett

275 2012). Prior to statistical tests, EFR amplitudes at signal frequencies were acquired

276 through Fast Fourier Transformation (FFT) in MATLAB (MathWorks) similar to (Lai

277 and Bartlett 2018). 
279 For MLR statistics, P1, N1, P2, and N2 (Fig. 5A) peaks were measured at each time

280 point, corresponding to subcortical (P1), thalamocortical (N1) and cortical sources

281 (P2, N2) (Simpson and Prendergast 2013). Peak amplitudes were normalized to the

282 pre-blast exposure baseline measurements for display in Fig. 5C, D. The normalized

283 peak amplitudes at each time point were compared to the pre-stimulus baseline

284 using a paired sign-rank test, with a 0.05 significance criterion.

286 For IRN statistics, we performed moving-window autocorrelations in $25 \mathrm{msec}$ moving

287 windows (5 msec steps) on each response waveform to simulate physiological

288 tracking of temporal periodicity. Peak autocorrelation frequency was defined by the

289 inverse of the time lag where peak autocorrelation value occurs in each window. This

290 process yielded a peak frequency that reflect the frequency representation of the

291 IRN auditory response for each of the 51 time windows in total (see Fig. 8B). Of

292 those, 45 occurred during the stimulus. The peak frequencies were then compared

293 to the "pseudopitches" of the IRN stimuli on corresponding time points. A value within

$2945 \mathrm{~Hz}$ of absolute difference to corresponding "pseudopitch" was considered "tracked."

295 We used this number of "tracked" peak frequencies, or "pitch-tracking score," as a

296 quantification for IRN performance. The significance of each main effect (time, blast

297 condition, and IRN iterations) and interaction was assessed using similar 2-way

298 repeated measures ANOVA test as ABR statistics $(\alpha=0.05)$. For

299 response-to-response correlation (Fig. 8D), the cross-correlation was measured 
between the response to the IRN stimuli pre-exposure and the response to the same stimulus post-exposure. Blast versus sham group was tested using the paired sign-rank test for this measure $(\alpha=0.05)$.

\section{Results}

\section{A. ABR and MLR}

\section{ABR Thresholds}

\section{(Insert Fig. 2 about here)}

Click ABR recordings captured distinctive courses of threshold changes over the two months post-exposure for blast and sham animals (Fig. 2). A large, $>30 \mathrm{~dB}$ SPL maximum threshold increase was observed in post-blast-exposure animals (Fig. 2, red lines). Adjacent animals exposed only to blast noise (Sham) did not undergo significant threshold shifts (Fig. 2, blue lines). Thresholds for blast group animals showed clear recovery during the first two weeks, with the largest changes occurring between 4 days - 10 days. Thresholds for blast-exposed animals remained significantly elevated (worse) than those of sham animals throughout the two months post-exposure that were measured (Simple Main Effects, day 30: df=1.000, $F=10.904, p=0.005 ;$ day $60: d f=1.000, F=12.727, p=0.003)$. Significant main effects of both Group ( $\left.\mathrm{df}=1.000, \mathrm{~F}=61.943, \mathrm{p}=<0.001, \mathrm{\eta}_{\mathrm{p}}^{2}=0.816\right)$ and Time Point $(\mathrm{df}=2.554$, $F=41.932, p<0.001, \eta^{2}{ }_{p}=0.750$ ), as well as a significant Group ${ }^{*}$ Time Point interaction effect $\left(d f=2.554, F=23.503, p<0.001, \eta^{2}{ }_{p}=0.627\right)$, were observed. 
322 Similar trends were observed with tone ABR recordings of $8 \mathrm{kHz}$ and $16 \mathrm{kHz}$ (Fig. 2),

323 with a significant $(p \leq 0.001)>30 \mathrm{~dB}$ increase in threshold within 48 hours

324 post-blast-exposure and most prominent recovery between 4 days -10 days. $8 \mathrm{kHz}$

325 threshold differences between blast conditions became non-significant ((Simple

326 Main Effects, $\mathrm{df}=1.000, \mathrm{~F}=3.151, \mathrm{p}=0.098$ ) at 10 days post-blast. At two weeks

327 post-exposure, $16 \mathrm{kHz}$ thresholds remained significantly elevated (Simple Main

328 Effects, $d f=1.000, F=16.527, p<0.001$ ), after which point the thresholds for the two

329 chosen tone frequencies were no longer significantly different between Blast and

330 Sham. Our rmANOVA analysis using Group and Time Points as factors showed

331 significant main effects of Group ( $8 \mathrm{kHz}$ : df=1.000, $F=10.847, p=0.005, \eta^{2}{ }_{p}=0.437 ; 16$

$\left.332 \mathrm{kHz}: \mathrm{df}=1.000, \mathrm{~F}=19.697, \mathrm{p}<0.001, \eta^{2}{ }_{\mathrm{p}}=0.585\right)$, Time $(8 \mathrm{kHz}: \mathrm{df}=3.924, \mathrm{~F}=25.837$,

$\left.333 \quad p<0.001, \quad \eta_{p}^{2}=0.649 ; 16 \mathrm{kHz}: \quad d f=3.043, \quad F=20.181, \quad p<0.001, \quad \eta^{2}=0.590\right)$ and

334 Group ${ }^{\star}$ Time Point interaction (8 kHz: df=3.924, $F=13.490, p<0.001, \eta^{2}=0.491 ; 16$

$\left.335 \mathrm{kHz}: \mathrm{df}=3.043, \mathrm{~F}=15.860, \mathrm{p}<0.001, \eta^{2}=0.531\right)$ for $8 \mathrm{kHz}$ and $16 \mathrm{kHz}$ threshold

336 respectively. These results demonstrate that broadband click thresholds remain

337 significantly elevated over the 60 days measurement window. $8 \mathrm{kHz}$ thresholds

338 largely returned to baseline (Day 30: $8 \mathrm{~dB}$ difference, $t=3.197, p=0.118$; day $60: 4 \mathrm{~dB}$

339 difference, $\mathrm{t}=1.598, \mathrm{p}=0.965)$ after two weeks, and $16 \mathrm{kHz}$ thresholds remained

340 significantly elevated compared to pre-blast baseline according to post hoc analysis

341 (Day 30: $15.5 \mathrm{~dB}$ difference, $\mathrm{t}=5.687, \mathrm{p}<0.001$; day 60: $14.5 \mathrm{~dB}$ difference, $\mathrm{t}=5.320$,

$342 \mathrm{p}<0.001$ ), although the difference between blast and Sham was not significant at 
343 these time points.

ABR Amplitudes

(Insert Fig. 3 about here)

For our ABR and MLR measurements, we used two sound levels: $80 \mathrm{~dB}$ SPL was

chosen because it is commonly used in auditory evoked potential studies in rat and

elicits clear ABR responses in all except the most extreme cases of blast-exposure.

In order to compensate for changes in threshold induced by blast exposure, we also

measured $\mathrm{ABR}$ amplitudes at $30 \mathrm{~dB}$ SL above threshold (sensation level, or SL).

This enabled us to separate changes in ABR amplitudes due to audibility (threshold)

versus those due to threshold-independent changes in subcortical auditory signaling.

Note that we did not attempt to compare later ABR waves with equivalent wave I amplitudes, as in Lai et al. (2017).

ABR wave amplitudes were assessed for wave I (putative auditory nerve), III (putative cochlear nuclei), and V (putative rostral brainstem and inferior colliculus) in response to click stimuli at $80 \mathrm{~dB}$ SPL (Fig. 3) and $30 \mathrm{~dB}$ SL (Fig. 4). Repeated measures statistics for $80 \mathrm{~dB}$ SPL and 30dB SL are shown in Tables 1-4.

Wave I: Wave I amplitudes at $80 \mathrm{~dB}$ SPL for all ABR carriers at $80 \mathrm{~dB}$ SPL exhibited 
at all time points tested in blast animals for clicks, $8 \mathrm{kHz}$ tones, and $16 \mathrm{kHz}$ tones, indicating lasting cochlear/auditory nerve damage (Table 4). No significant changes in wave I amplitudes were observed in Sham exposed animals at any time point.

Wave III: Wave III amplitudes at $80 \mathrm{~dB}$ SPL for all ABR carriers at $80 \mathrm{~dB}$ SPL exhibited significant main effects of Group, Time, and Group*Time interaction (Table 1), with Group effects lasting for 14 days for Click and $16 \mathrm{kHz}$ tones and 10 days for $8 \mathrm{kHz}$ tones. Compared to pre-exposure responses, wave III amplitudes were significantly smaller at all time points tested in blast animals for clicks and $16 \mathrm{kHz}$ tones and up to 30 days for $8 \mathrm{kHz}$ tones, indicating lasting declines in cochlear nucleus excitation (Table 4). No significant changes in wave III amplitudes were observed in Sham exposed animals at any time point.

Wave V: Wave $V$ amplitudes at $80 \mathrm{~dB}$ SPL for all ABR carriers at $80 \mathrm{~dB}$ SPL exhibited significant main effects of Group, Time, and Group*Time interaction (Table 1), with Group effects lasting for 14 days for Click and $16 \mathrm{kHz}$ tones and 7 days for 8 $\mathrm{kHz}$ tones. Compared to pre-exposure responses, wave $\mathrm{V}$ amplitudes were significantly smaller at all time points tested in blast animals for clicks, indicating lasting declines in rostral brainstem/IC excitation for brief, broadband clicks (Table 4). However, decreases in wave $\mathrm{V}$ amplitudes persisted for only 7 days for $8 \mathrm{kHz}$ tones and 14 days for $16 \mathrm{kHz}$ tones, suggesting that despite decreases in cochlear nucleus excitation (as represented by wave III amplitude), rostral brainstem/IC responses compensated and restored their responses. No significant changes in wave $\mathrm{V}$ amplitudes were observed in Sham exposed animals at any time point except for a 
387

388

389

390

391

392

small decline for $16 \mathrm{kHz}$ responses 60 days post Sham exposure (Table 4).

\section{(Insert Fig. 4 about here)}

The effects on $A B R$ waves were greatly diminished when responses to $30 \mathrm{~dB} S L$ sounds were measured, as shown in Table 2 and Table 3. For Wave I, significant main effects of Time (Click: $d f=4.360, F=2.554, p=0.043, \eta^{2}=0.154 ; 8 \mathrm{kHz}: \mathrm{df}=4.264$, $\left.F=3.146, p=0.018, \eta^{2}=0.183 ; 16 \mathrm{kHz}: \mathrm{df}=4.469, \quad F=2.325, p=0.031, \eta^{2}{ }_{p}=0.142\right)$ but not Group (Click: df=1.000, F=3.637, $p=0.077, \eta^{2}{ }_{p}=0.206 ; 8 \mathrm{kHz}: \mathrm{df}=1.000, F<0.001$, $\left.p=0.994, \eta_{p}^{2}<0.001 ; 16 \mathrm{kHz}: \mathrm{df}=1.000, F=1.046, p=0.324, \eta^{2}{ }^{2}=0.070\right)$ were observed for click, $8 \mathrm{kHz}$, and $16 \mathrm{kHz}$. Additionally, significant Group*Time interaction effects were only observed for Click ( $\left.d f=4.360, F=2.630, p=0.039, \eta^{2}=0.158\right)$ and $16 \mathrm{kHz}$ $\left(d f=4.469, F=2.381, p=0.027, \eta^{2} p=0.145\right)$. Simple main effects of Group $(d f=1.000)$ were only observed in Click (Table 3).

Compared to pre-exposure responses, wave I and $\mathrm{V}$ responses to clicks were significantly reduced 1 day post-blast and wave III responses were significantly reduced days $1-4$. Otherwise, there were no significant declines in wave amplitudes in the Blast group, and there were no significant amplitude changes in the Sham group.

\section{(Insert Fig. 5 about here)}


In order to observe thalamocortical and cortical neural transmission in response to

411 acoustic transients, we recorded middle-latency auditory responses to click and 8

$412 \mathrm{kHz}$ tone stimuli. These stimuli were identical to those used for $\mathrm{ABR}$, but the

413 presentation rate was much slower, and the analysis window and filters were different (see Methods). Measurements were made for the first four main peaks of

415 the MLR. Here, P1 corresponds to subcortical activity, largely encompassing the

416 ABR. N1 corresponds to thalamocortical transmission, while P2 and N2 are thought to correspond to primarily cortical activity (Deiber et al. 1988; Liégeois-Chauvel et al. 1994; Tichko and Skoe 2017; Musiek and Nagle 2018).

$80 \mathrm{~dB}$ SPL responses

421 In blast animals, all waves were decreased relative to pre-blast baseline for days 1-7

422 post-blast ( $p<0.05$, sign-rank test) in response to $80 \mathrm{~dB}$ SPL click stimuli. Simple Main

423 effect of blast showed similar results for P1, N1 and P2 (Table 5). Grand average

424 traces are shown for MLR responses in this time window in Fig. 5A, relative to the

425 pre-blast waveform (thick blue line in A-D). Even after the blast, the morphology and

426 timing of the MLR waveform remained relatively intact, but the amplitudes were

427 significantly diminished, shown as a significant Time*Group interaction effect for all

428 three waves of interest $\left(P 1: d f=2.942, F=4.111, p=0.014, \eta^{2}{ }_{p}=0.255 ; N 1: d f=3.460\right.$,

$\left.429 \quad F=7.786, p<0.001, \eta^{2} p=0.393 ; P 2: d f=3.684, F=5.607, p=0.001, \eta^{2} p=0.318\right)$. In Fig.

$4305 \mathrm{E}-\mathrm{H}$, wave amplitudes were normalized to the pre-blast waves and measured. 
431 Between 7 and 10 days, the early P1 wave recovers to within $10-15 \%$ of its baseline

432 amplitude, whereas the later waves recovered more slowly (Fig. 5E). In particular, the

433 N1 wave, thought to reflect thalamocortical transmission (Barth and Shi Di 1991;

434 McGee et al. 1991, 1992; Di and Barth 1992; Brett et al. 1996; McGee and Kraus

435 1996; Phillips et al. 2011; Šuta et al. 2011), remained significantly lower in blast

436 animals even 60 days post-blast $(p<0.05$, sign-rank test, Fig. $5 E)$. By contrast, the

437 MLR waves in sham animals were largely stable across the measurement time (Fig.

438 5F). Although there was some decline in the later waves for the last time window, this

439 was not statistically significant (Fig. 5B, D, F).

MLR responses to $8 \mathrm{kHz}, 80 \mathrm{~dB}$ SPL tone pips largely mirrored the results to clicks,

442 with significant decreases for all waves for post-blast days 1-7 and a lasting decline

443 in $\mathrm{N} 1$ for the duration of measurements ( $\mathrm{p}<0.05$, sign-rank test, traces not shown).

444 Sham responses did not show any significant changes in MLR waves in response to 445 the $80 \mathrm{~dB}$ SPL tone pips.

\section{$30 \mathrm{~dB} S L$}

448 MLR responses to clicks at $30 \mathrm{~dB}$ SL were reduced in Blast animals 1 day after the

449 blast but recovered to baseline levels afterwards. There was a tendency towards

450 elevated P1 amplitudes, but this was not significant (Fig. 5G). Sham animals did not

451 show any significant changes, though there was a tendency towards an increase in

452 wave amplitude (Fig. $5 \mathrm{H}$ ). Similar results were found for responses to tones at $30 \mathrm{~dB}$ 
453

454

455

SL (not shown).

Given the different time courses and extents of ABR threshold change for clicks and tones, we measured the corresponding EFRs in response to Gaussian broadband noise (nSAM), $8 \mathrm{kHz}$, and $16 \mathrm{kHz}$ sinusoidal tone carriers. Considering that slow AM $(<50 \mathrm{~Hz})$ and faster AM $(>50 \mathrm{~Hz})$ are differentially represented throughout cortical and subcortical auditory nuclei (Joris et al. 2004; Wang et al. 2008), three representative AMFs (10, 45, and $256 \mathrm{~Hz})$ were selected from previous publications (Parthasarathy et al. 2010, 2014; Parthasarathy and Bartlett 2011, 2012; Race et al. 2017) and tested in quiet at $100 \%$ and $50 \%$ modulation depth. AM stimuli were also presented at $30 \mathrm{~dB}$ SL with a $71 \mathrm{~Hz}$ sinusoidally AM masker of the same length and onset, with Gaussian noise as the carrier, at 20dB SNR and 0 SNR relative to the sound level of target AM. Responses were collected from both electrodes, but for 10 and $45 \mathrm{~Hz}$ AMFs, channel 2 responses were analyzed; and for $256 \mathrm{~Hz}$ AMF, channel 1 responses were analyzed (see Methods). For each carrier, simple main effects of all conditions were analyzed.

(Insert Fig. 6 about here)

EFRs in quiet: For all three carriers in quiet, EFR amplitudes were similar at 10 and $256 \mathrm{~Hz}$ across time points and AM modulation depths (Fig. 6). Overall, the nSAM FFT amplitudes were higher in the Blast group in quiet $(\mathrm{df}=5.000, \mathrm{~F}=9.629, \mathrm{p}=0.008$, 
475

476

477

478

479

480

481

482

483

484

485

486

487

488

489

490

491

492

493

494

495

496

$\left.\eta_{p}^{2}=0.426\right)$, with $45 \mathrm{~Hz}$ being the most affected. Interestingly, in contrast to the lower FFT Amplitude found in Blast AM at $80 \mathrm{~dB}$ SPL (Race et al. 2017), when $30 \mathrm{~dB}$ sensation level (threshold $+30 \mathrm{~dB}$ ) was to compensate for threshold differences, FFT amplitude of $45 \mathrm{~Hz}$ nSAM was higher in Blast than in Sham animals (Fig. 6B). This difference was most salient on day 7 for $45 \mathrm{~Hz}$ nSAM (Post hoc comparison: $\mathrm{t}=-4.122, \mathrm{p}=0.006)$. For $8 \mathrm{kHz}$ SAM and $16 \mathrm{kHz}$ SAM, the slight elevation of AM FFT Amplitude in Blast animals was not significant (Fig. 6C and 6D). Surprisingly, time did not have a significant interaction across repeated measures for AM response with any carrier either.

EFR in noise: Not surprisingly, Noise level and Modulation Depth both had a significant repeated measures effect on nSAM (Noise level: $\mathrm{df}=2.000, F=263.217$, $p<0.001, \eta^{2}{ }_{p}=0.953 ;$ Depth: $\left.d f=1.000, F=455.655, p<0.001, \eta^{2}{ }_{p}=0.972\right), 8 \mathrm{kHz}$ SAM (Noise level: $d f=2.000, F=19.308, p<0.001, \eta_{p}^{2}=0.580$; Depth: $d f=1.000, F=72.031$, $\mathrm{p}<0.001, \eta^{2}=0.837$ ) and $16 \mathrm{kHz}$ SAM (Noise level: $d f=2.000, F=16.691, p<0.001$, $\eta^{2}{ }_{p}=0.544$; Depth: $\left.d f=1.000, F=49.742, p<0.001, \eta^{2}{ }_{p}=0.780\right)$. Noise level and Depth also have a significant interaction effect with Groups for nSAM overall (Noise level: $d f=2.000, \quad F=10.295, \quad p<0.001, \quad \eta^{2}{ }_{p}=0.442 ; \quad$ Depth: $d f=1.000, \quad F=6.057, \quad p=0.029$, $\eta_{p}^{2}=0.318$ ), showing blast nSAM responses as less affected 20 SNR noise, but more sensitive to AM attenuation for lower modulation depth (Fig. 7B). Noise level also affect sham animals less than blast animals for $8 \mathrm{kHz}$ SAM overall, showing a significant interaction effect with Group ( $d f=2.000, F=5.696, p=0.008, \eta^{2}{ }_{p}=0.289$, Fig. 
497 7C). These conditions do not have significant interaction effects with Group on 16

$498 \mathrm{kHz}$ SAM (data not shown). Noise level had significant interaction effects with both

499 Group $\left(\mathrm{df}=2.000, \mathrm{~F}=6.130, \mathrm{p}=0.011, \mathrm{\eta}^{2} \mathrm{p}=0.320\right)$ and Depth $(\mathrm{df}=2.000, \mathrm{~F}=19.438, \mathrm{p}$

$\left.500<0.001, \eta^{2}{ }_{p}=0.599\right)$ for nSAM $45 \mathrm{~Hz}$, while the effect of Time or Depth between

501 Groups is not significantly different for any modulation frequency.

502

(Insert Fig. 7 about here)

505 For $8 \mathrm{kHz}$ SAM, the effects of Noise level were applied differently between Groups,

506 as significant interaction effects were observed between Noise and Group for $10 \mathrm{~Hz}$

$507\left(\mathrm{df}=2.000, \mathrm{~F}=12.795, \mathrm{p}=0.001, \mathrm{n}_{\mathrm{p}}{ }_{\mathrm{p}}=0.477\right)$ and $45 \mathrm{~Hz}(\mathrm{df}=2.000, \mathrm{~F}=4.878, \mathrm{p}=0.015$,

$\left.508 \eta^{2}{ }_{p}=0.258\right)$ modulation frequencies, though not for $256 \mathrm{~Hz}$ (data not shown). Most

509 notably, sham $8 \mathrm{kHz}$ SAM EFRs showed greater resilience to competing noise at 10

$510 \mathrm{~Hz}$ modulation frequency (Fig. 7C), contrary to the trends observed in nSAM.

511 Modulation Depth affects FFT amplitude without regard to blast condition, with no

512 significant interaction effects with Group observed. For $16 \mathrm{kHz}$ SAM, none of the

513 parameters tested had significantly different effects between Groups at $30 \mathrm{~dB}$ SL

514 (not shown).

515

516 Overall, Blast and Sham animals generally decreased EFR amplitudes with

517 increased noise, especially for $0 \mathrm{~dB}$ SNR. Similar to quiet, $45 \mathrm{~Hz}$ amplitudes were

518 most affected, with increases in EFR amplitudes in Blast animals that were most 
519 pronounced in the 7-14 day window (Fig. 7B). The effects and interactions of blast

520 exposure and competing noise were dependent on both modulation frequency and

521 time after exposure..

522

523

D. IRN

524 Time-varying IRN stimuli (Fig. 8A) were used to elicit frequency-following response

525 (FFR) mimicking Mandarin tone 2 (T2, rising) and tone 4 (T4, falling) pitch contours

526 to measure pitch-tracking ability using a broadband speech-like carrier at $30 \mathrm{~dB} \mathrm{SL}$,

527 similar to what has been measured in human studies of auditory learning and

528 hearing loss (Anderson et al. 2010, 2013; Skoe and Kraus 2010). We used

529 autocorrelation interval contours that simulated pitches similar to the forms of rising

530 (T2) and falling (T4) pitch contours of the Mandarin Chinese vowel /yi/ (Krishnan et al.

$5312014,2015,2017 a, 2017 b)$. IRN responses collected from channel 1 were evaluated

532 based on the pitch-tracking score (Fig. 8B), which measures the number of time

533 windows where the dominant autocorrelation frequency of the response matches

534 that of the IRN stimulus autocorrelation frequency (see Methods). In general, we

535 observed a loss of pitch-tracking fidelity in Blast animals over the two months

536 post-exposure (Fig. 8B and $8 \mathrm{C}$ ). Even for the most salient pitch (32 Iterations), blast

537 exposure had a significant Group effect on pitch-tracking scores in both Tone 2

$538\left(\mathrm{df}=1.000, \mathrm{~F}=6.495, \mathrm{p}=0.026, \eta^{2}=0.351\right)$ and Tone $4(\mathrm{df}=1.000, F=6.115, \mathrm{p}=0.029$,

$539 \eta^{2}{ }_{p}=0.338$ ), with the largest mean differences on day $7-10$. The interaction effect

540 between Time and Group was not significant. 
541 Blast exposure significantly changed the neural response's morphology to IRN at 30

$542 \mathrm{~dB}$ SL $(p=0.016$, paired sign-rank test, Fig. 8D), such that the cross-correlation

543 between the pre-exposure response and the post-exposure response was much

544 lower in the Blast group up to 30 days post-blast.

545 (Insert Fig. 8 about here)

546

IRN iterations: As expected, reduced pitch salience, controlled by reducing iteration

number, affected pitch-tracking responses in animals $(\mathrm{df}=4.000, F=41.697, p<0.001$,

$\left.549 \quad \eta_{p}^{2}=0.777\right)$, also showing a significant interaction effect with Time post-exposure

$550\left(\mathrm{df}=20.000, \mathrm{~F}=1.722, \mathrm{p}=0.031, \mathrm{n}_{\mathrm{p}}{ }_{\mathrm{p}}=0.125\right)$. Specifically, pitch-tracking performances

551 to 32 iterations and 16 iterations worsened significantly up to 7-10 days

552 post-exposure, with various degrees of recovery over the following time course. Both

553 the Blast and Sham group exhibited worse pitch tracking with reduced iterations

554 (salience) and to a similar degree. No significant interaction effects with Group were

555 observed for Time and Iterations (Fig 9).

$556 \quad$ (Insert Fig. 9 about here)

557

558

559

560

561

562

\section{Discussion}

This study examined the time course of recovery from a single mild blast injury using simple and complex auditory stimuli longitudinally at dense time points for two months. The largest blast-induced threshold shifts and changes in evoked potentials diminished within two weeks. At 30-60 days post-blast, lingering increases in click 
563 (but not tone) thresholds, decreases in MLR N1 (thlamocortical) amplitude, and

564 declines in pitch-tracking of speech-like IRN pitch trajectories were observed.

565 Compensating for threshold shift and using $30 \mathrm{~dB}$ sensation level for AM stimuli, we

566 found that responses to sinusoidal AM stimuli in quiet or noise recovered within 14

567 days. The 7-14 day window was particularly rapid in the recovery of many auditory

568 parameters.

\section{Lasting changes from a single mild blast}

571 This study has examined injuries elicited by a single dorsal blast exposure with body

572 shielding that did not result in tympanic membrane ruptures, which we and others

573 characterize as a "mild" blast exposure. Therefore, the deficits observed may not be

574 as drastic as that documented by some previous studies in which the injuries were

575 caused by more intense or multiple exposures (Cho et al. 2013b; Du et al. 2013; Luo

576 et al. 2014a, 2014b; Mahmood et al. 2014), often resulting in death or tympanic

577 membrane rupture. The distribution of injuries also differed from models in which

578 blast exposure comes from different orientations, as predicted in animals (Chavko et

579 al. 2011; Dal Cengio Leonardi et al. 2012) and computational studies (Hua et al.

580 2017; Unnikrishnan et al. 2019). These differences in pressure wave amplitude,

581 duration, and propagation patterns would affect both the distribution and severity of

582 damage across the brain. Compared to other orientations, including top-facing

583 exposure as in our model, head-facing exposure is known to produce the highest

584 peak pressure and prolonged pressure wave propagation, while side-facing 
585

586

exposure produced lower peak pressure and pressure increase rate in rat model (Chavko et al. 2011; Dal Cengio Leonardi et al. 2012). Although these could change the potential mechanisms of recovery and compensation, it is likely that all blast exposures undergo a multi-stage recovery process similar to that observed in the present study. In our model, the overpressure blast wave passes through the entire rat brain, such that TBI can be observed throughout the brain, including the frontal cortex and in multiple thalamic regions (Walls et al. 2016), and it results in increased ventral BBB membrane permeation and inflammation, encompassing many subcortical auditory nuclei and axonal tracts. The non-invasive physiological measurements in this study may be indicators of more widespread blast damage in auditory and may be correlated with damage in non-auditory brain regions.

\section{ABR}

We documented a $>30 \mathrm{~dB}$ peak increase in threshold for click, $8 \mathrm{kHz}$, and $16 \mathrm{kHz}$ (Fig. 2) during the first 4 days, consistent with the description of $\mathrm{IHC}$ and $\mathrm{OHC}$ disturbances across a wide range of frequencies due to blast overpressure as stated in multiple previous publications (Patterson and Hamernik 1997; Ewert et al. 2012; Race et al. 2017). Although this broadband threshold shift extended to the last time point at 60 days, the $\sim 10 \mathrm{~dB}$ difference would not be considered clinically relevant and suggests .

Rapid improvements in ABR threshold and wave amplitudes were observed in the 7-10 days recovery period for waves I, wave III, and wave V (Fig. 3). Notably, wave V 
607 amplitude recovered earlier than wave I, possibly indicating the role of compensation

608 in auditory midbrain as one of the post-blast recovery mechanisms.

609

610 ABR parameters showed two waves of post-blast changes: one between 1-10 days

611 post-exposure, and one 10-30 days, as evidenced by Figs. 2 and 3. We hypothesize

612 that these two waves of deficits indicated a series of secondary biochemical impacts

613 surrounding CAS (Laplaca et al. 1997; Knudsen and Øen 2003; Hamann et al. 2008;

614 Garman et al. 2011; Säljö et al. 2011; Luo et al. 2014a, 2014b; Song et al. 2015;

615 Walls et al. 2016). In the initial recovery window, we observed changes in $A B R$

616 waveforms over and above those expected by threshold shifts, whereas for days 10

617 and afterwards, there were changes observed at $80 \mathrm{~dB}$ SPL but not for $30 \mathrm{~dB}$ SL.

618 Our observations of blast recovery were mostly consistent with the notion of changes

619 over the first week due to secondary damage that is substantially repaired over the

620 second week.

621

622 MLR

623 At $80 \mathrm{~dB}$ SPL, we found persistent deficits in thalamocortical and cortical

624 transmission based on the N1, P2 and N2 peaks (Fig. 5A vs. B, C vs. D), which were

625 affected at 30 and 60 days, even after the early P1 response had fully recovered (Fig

$6265 \mathrm{E})$. These deficits were not present at $30 \mathrm{~dB}$ SL, suggesting that effects were at

627 least partially due to small shifts in auditory thresholds (Fig. 5G). In veterans and the

628 general population with lifetime noise exposure, MLR responses were shown to be 
smaller even when subjects had clinically normal audiograms, and there was some evidence of increased cortical gain (Valderrama et al. 2018; Bramhall et al. 2020). In another study with blast-exposed veterans, most of the changes in auditory-evoked potentials were correlated with hearing loss (Meehan et al. 2019). Together, these results suggest that hearing loss may be the main contributor to MLR changes leading to declines in suprathreshold responses.

\section{Amplitude Modulation EFRs}

The current study extended an earlier study (Race et al. 2017) to include EFR responses to more challenging auditory stimuli, including lower modulation depth (Fig 6) and in the presence of modulated noise (Fig 7). The Race et al. (Race et al. 2017) study revealed differences in AM processing at $80 \mathrm{~dB}$ SPL between Blast and Sham animals, such that blast animals had lower AM FFR amplitudes mainly for AM frequencies $\leq 50 \mathrm{~Hz}$. However, when the hearing threshold has been compensated, the differences in AM FFR amplitude diminished and even changed sign (Fig. 6), suggesting that both changes in audibility and changes in the gain of subcortical auditory system are critical contributors to AM FFR deficits in the blast-exposed auditory system. There are complicated interactions between the AM FFR amplitudes, blast exposure, and the presence of noise, evident as a persistent Group ${ }^{*}$ Noise Level interaction effect in both nSAM and $8 \mathrm{kHz}$ SAM. AM responses consist of contributions from multiple generators along the auditory neuraxis, with cortical generators contributing mainly to lower AMFs $<50 \mathrm{~Hz}$, and higher frequency 
651 AM responses limited to nuclei lower in the auditory neuraxis. The lack of

652 blast-induced differences at higher AMFs distinguishes the blast-induced damage

653 from age-related changes, which are most prominent at higher modulation

654 frequencies (Parthasarathy et al. 2010, Parthasarathy and Bartlett 2012, Lai et al. 655 2017).

656

657 The differences in low-middle AMFs were manifested in opposed directions under 658 slow $(10 \mathrm{~Hz})$ and middle $(45 \mathrm{~Hz})$ AMFs: notably, repeated measures testing showed 659 that FFT amplitudes of $8 \mathrm{kHz}$ SAM in noise are lower for Blast at $10 \mathrm{~Hz}$ modulation 660 frequency (Day 4 quiet, $100 \%$ depth: Blast mean $=0.496 \mathrm{mV}$, Sham mean $=0.704 \mathrm{mV}$ ), 661 but higher for Blast at $45 \mathrm{~Hz}$ (Day 4 quiet, $100 \%$ depth: Blast mean=0.898 mV, Sham 662 mean=0.733 $\mathrm{mV}$; Fig 7C). This dichotomy is ripe for further study since the $10 \mathrm{~Hz}$ 663 and $45 \mathrm{~Hz}$ modulations represent different temporal processing regimes and 664 components of speech (Rosen 1992). If these modulation frequency bands are 665 differentially altered by blast, it may skew the cochlear-filtered envelope and impair 666 hearing in complex listening environments (Chabot-Leclerc et al. 2016).

\section{IRN EFRs}

669 Complex temporal periodicity between $50 \mathrm{~Hz}$ and $500 \mathrm{~Hz}$ carries important speech 670 information such as voicing, stress and intonation (Rosen 1992). The present study 671 provided insights into blast-induced sound processing deficits through the use of an 672 IRN stimulus that simulates Chinese intonations and whose pitch and salience can 
673 be reliably controlled, showing that IRN can be a useful diagnostic tool for

674 neurotrauma. We found that even when click ABR thresholds have returned to

675 subclinical threshold shifts, the deficits in pitch-tracking response to IRN tone stimuli,

676 lingered at least 30 days post-exposure (Figs. 8D).

677 Both Blast and Sham animals showed an overall reduction in tracking with

678 decreased salience through decreased iterations in IRN, but differential effects were

679 noted mainly only in the first two weeks. A previous study showed that increased IRN

680 iterations improved auditory stream segregation in normal hearing veterans more

681 than hearing-impaired veterans (Thompson and Marozeau 2014). Our IRN data

682 (Figs. 8-9) suggest that more dynamic and speech-like modulation changes do not

683 recover quickly or completely from even a single mild blast exposure.

\section{Acknowledgments}

686 The authors would like to thank Jonathan Tang, Brandon Coventry, Alex Sommers,

687 Nanami Miyazaki, and all the other members in Central Auditory Processing Lab and

688 Lab of Translational Neuroscience for their generous assistance in the completion of 689 this study.

\section{Author contributions}

692 Study concept and design: Edward Bartlett, Riyi Shi, Emily X. Han, Joseph M.

693 Fernandez.

694 Animal Blast Exposure: Joseph M. Fernandez. 
695 Electrophysiology: Emily X. Han, Caitlin Swanberg.

696 Data analysis and interpretation: Emily X. Han, Edward Bartlett, Joseph M.

697 Fernandez.

698 Writing of the manuscript: Emily X. Han, Edward Bartlett.

699 Critical revision of the manuscript: Riyi Shi, Joseph M. Fernandez, Caitlin Swanberg.

700 Study supervision and obtainment of funding: Edward Bartlett, Riyi Shi.

$702 \quad$ Funding

703 This study is funded by Indiana CTSI 11917 and NIH T32DC016853.

704

705 Disclosures

706 Riyi Shi is a co-founder of Neuro Vigor, a company developing novel drug treatments

707 and diagnostic approaches for neurodegenerative diseases and neurotrauma. 
710 Alsindi S, Patterson RD, Sayles M, Winter IM. The responses of single units to

711 simple and complex sounds from the superior olivary complex of the Guinea pig. In:

712 Acta Acustica united with Acustica. S. Hirzel Verlag GmbH, 2018, p. 856-859.

713 Alvarado JC, Fuentes-Santamaría V, Jareño-Flores T, Blanco JL, Juiz JM.

714 Normal variations in the morphology of auditory brainstem response (ABR)

715 waveforms: A study in wistar rats. Neurosci Res 73: 302-311, 2012.

716 Anderson S, Parbery-Clark A, White-Schwoch T, Kraus N. Auditory brainstem

717 response to complex sounds predicts self-reported speech-in-noise performance. $J$

718 Speech, Lang Hear Res 56: 31-43, 2013.

719 Anderson S, Skoe E, Chandrasekaran B, Kraus N. Neural timing is linked to

720 speech perception in noise. J Neurosci 30: 4922-4926, 2010.

721 Barth DS, Shi Di. The functional anatomy of middle latency auditory evoked

722 potentials. Brain Res 565: 109-115, 1991.

723 Bendor $\mathbf{D}$, Wang $\mathbf{X}$. The neuronal representation of pitch in primate auditory cortex.

$724 \quad$ Nature 436: 1161-1165, 2005.

725 Berger G, Finkelstein Y, Avraham S, Himmelfarb M. Patterns of hearing loss in

726 non-explosive blast injury of the ear. $J$ Laryngol Otol 111: 1137-1141, 1997.

727 Bharadwaj HM, Masud S, Mehraei G, Verhulst S, Shinn-Cunningham BG.

728 Individual differences reveal correlates of hidden hearing deficits. J Neurosci 35:

$729 \quad 2161-2172,2015$.

730 Bramhall NF, Niemczak CE, Kampel SD, Billings CJ, McMillan GP. Evoked 
731 Potentials Reveal Noise Exposure-Related Central Auditory Changes Despite

732 Normal Audiograms. Am J Audiol 29: 152-164, 2020.

733 Bressler S, Goldberg H, Shinn-Cunningham B. Sensory coding and cognitive

734 processing of sound in Veterans with blast exposure. Hear Res 349: 98-110, 2017.

735 Brett B, Krishnan G, Barth DS. The effects of subcortical lesions on evoked

736 potentials and spontaneous high frequency (gamma-band) oscillating potentials in rat

737 auditory cortex. Brain Res 721: 155-166, 1996.

738 Caspary DM, Ling L, Turner JG, Hughes LF. Inhibitory neurotransmission, plasticity

739 and aging in the mammalian central auditory system. $J$ Exp Biol 211: 1781-1791,

2008.

741 Caspary DM, Schatteman T a, Hughes LF. Age-related changes in the inhibitory

742 response properties of dorsal cochlear nucleus output neurons: role of inhibitory

743 inputs. J Neurosci 25: 10952-9, 2005.

744 Cave K, Cornish EM, Chandler DW. Blast Injury of the Ear: Clinical Update from the

745 Global War on Terror. Mil Med 172: 726-730, 2007.

746 Chabot-Leclerc A, MacDonald EN, Dau T. Predicting binaural speech intelligibility

747 using the signal-to-noise ratio in the envelope power spectrum domain. J Acoust Soc

$748 \quad A m$ 140: 192-205, 2016.

749 Chavko M, Watanabe T, Adeeb S, Lankasky J, Ahlers ST, McCarron RM.

750 Relationship between orientation to a blast and pressure wave propagation inside the

751 rat brain. $J$ Neurosci Methods 195: 61-66, 2011.

752 Cho HJ, Sajja VSSS, VandeVord PJ, Lee YW. Blast induces oxidative stress, 
753 inflammation, neuronal loss and subsequent short-term memory impairment in rats.

$754 \quad$ Neuroscience 253: 9-20, 2013a.

755 Cho S II, Gao SS, Xia A, Wang R, Salles FT, Raphael PD, Abaya H, Wachtel J,

756 Baek J, Jacobs D, Rasband MN, Oghalai JS. Mechanisms of Hearing Loss after

757 Blast Injury to the Ear. PLoS One 8, 2013b.

758 Cohen JT, Ziv G, Bloom J, Zikk D, Rapoport Y, Himmelfarb MZ. Blast injury of the

759 ear in a confined space explosion: Auditory and vestibular evaluation. Isr Med Assoc J

$760 \quad 4: 559-562,2002$.

761 Dal Cengio Leonardi A, Keane NJ, Bir CA, Ryan AG, Xu L, VandeVord PJ. Head

762 orientation affects the intracranial pressure response resulting from shock wave

763 loading in the rat. J Biomech 45: 2595-2602, 2012.

764 Deiber MP, Ibañez V, Fischer C, Perrin F, Mauguière F. Sequential mapping

765 favours the hypothesis of distinct generators for $\mathrm{Na}$ and $\mathrm{Pa}$ middle latency auditory

766 evoked potentials. Electroencephalogr Clin Neurophysiol Evoked Potentials 71:

$767 \quad 187-197,1988$.

768 DePalma RG, Burris DG, Champion HR, Hodgson MJ. Current concepts: Blast

769 injuries. N. Engl. J. Med. 352Massachusetts Medical Society: 1335-1342, 2005.

770 Di S, Barth DS. The functional anatomy of middle-latency auditory evoked potentials:

771 Thalamocortical connections. J Neurophysiol 68: 425-431, 1992.

772 Du X, Ewert DL, Cheng W, West MB, Lu J, Li W, Floyd RA, Kopke RD. Effects of

773 antioxidant treatment on blast-induced brain injury. PLoS One 8: e80138, 2013.

774 Ewert DL, Lu J, Li W, Du X, Floyd R, Kopke R. Antioxidant treatment reduces 
blast-induced cochlear damage and hearing loss. Hear Res 285: 29-39, 2012.

Gallun FJ, Diedesch AC, Kubli LR, Walden TC, Folmer RL, Samantha Lewis S, McDermott DJ, Fausti SA, Leek MR. Performance on tests of central auditory processing by individuals exposed to high-intensity blasts. J Rehabil Res Dev 49: 1005-1024, 2012a.

Gallun FJ, Lewis MS, Folmer RL, Diedesch AC, Aud ;, Kubli LR, McDermott DJ, Walden TC, Fausti S a, Lew HL, Leek MR. Implications of blast exposure for central auditory function: a review. J Rehabil Res Dev 49: 1059-74, 2012b.

Garman RH, Jenkins LW, Switzer RC, Bauman RA, Tong LC, Swauger P V., Parks SA, Ritzel D V., Dixon CE, Clark RSB, Bayır H, Kagan V, Jackson EK, Kochanek PM. Blast Exposure in Rats with Body Shielding Is Characterized Primarily by Diffuse Axonal Injury. J Neurotrauma 28: 947-959, 2011.

Greenhouse SW, Geisser S. On methods in the analysis of profile data. Psychometrika 24: 95-112, 1959.

Van Haesendonck G, Van Rompaey V, Gilles A, Topsakal V, Van de Heyning P. Otologic Outcomes After Blast Injury: The Brussels Bombing Experience. Otol Neurotol 39: 1250-1255, 2018.

Hamann K, Durkes A, Ouyang H, Uchida K, Pond A, Shi R. Critical role of acrolein in secondary injury following ex vivo spinal cord trauma. $J$ Neurochem $107: 712-721$, 2008.

Hickox AE, Liberman MC. Is noise-induced cochlear neuropathy key to the generation of hyperacusis or tinnitus? J Neurophysiol 111: 552-564, 2014. 
797 Hua Y, Wang Y, Gu L. Primary blast waves induced brain dynamics influenced by

798 head orientations. Biomed Eng Lett 7: 253-259, 2017.

799 Joris PX, Schreiner CE, Rees A. Neural Processing of Amplitude-Modulated Sounds.

800 American Physiological Society, 2004.

801 Kerr AG. The effects of blast on the ear. J Laryngol Otol 94: 107-110, 1980.

802 Knudsen SK, Øen EO. Blast-induced neurotrauma in whales. Neurosci Res 46:

803 377-386, 2003.

804 Krishnan A, Gandour JT, Suresh CH. Cortical pitch response components show

805 differential sensitivity to native and nonnative pitch contours. Brain Lang 138: 51-60,

8062014.

807 Krishnan A, Gandour JT, Suresh $\mathbf{C H}$. Pitch processing of dynamic lexical tones in

808 the auditory cortex is influenced by sensory and extrasensory processes. Eur $J$

809 Neurosci 41: 1496-1504, 2015.

810 Krishnan A, Gandour JT, Xu Y, Suresh CH. Language-dependent changes in

811 pitch-relevant neural activity in the auditory cortex reflect differential weighting of

812 temporal attributes of pitch contours. J Neurolinguistics 41: 38-49, 2017a.

813 Krishnan A, Suresh CH, Gandour JT. Changes in pitch height elicit both

814 language-universal and language-dependent changes in neural representation of

815 pitch in the brainstem and auditory cortex. Neuroscience 346: 52-63, 2017b.

816 Kubli LR, Brungart D, Northern J. Effect of Blast Injury on Auditory Localization in

817 Military Service Members. Ear Hear 39: 457-469, 2018.

818 Kujawa SG, Liberman MC. Synaptopathy in the noise-exposed and aging cochlea: 
819 Primary neural degeneration in acquired sensorineural hearing loss. Hear Res 330:

820 191-199, 2015.

821 Lai J, Bartlett EL. Age-related shifts in distortion product otoacoustic emissions

822 peak-ratios and amplitude modulation spectra. Hear Res 327: 186-198, 2015.

823 Lai J, Bartlett EL. Masking Differentially Affects Envelope-following Responses in

824 Young and Aged Animals. Neuroscience 386: 150-165, 2018.

825 Lai J, Sommer AL, Bartlett EL. Age-related changes in envelope-following

826 responses at equalized peripheral or central activation. Neurobiol Aging 58: 191-200,

8272017.

828 Laplaca MC, Lee VMY, Thibault LE. An in vitro model of traumatic neuronal injury:

829 Loading rate-dependent changes in acute cytosolic calcium and lactate

830 dehydrogenase release. J Neurotrauma 14: 355-368, 1997.

831 Leung LY, VandeVord PJ, Dal Cengio AL, Bir C, Yang KH, King Al. Blast related

832 neurotrauma: A review of cellular injury. MCB Mol Cell Biomech 5: 155-168, 2008.

833 Lew HL, Garvert DW, Pogoda TK, Hsu P Te, Devine JM, White DK, Myers PJ,

834 Goodrich GL. Auditory and visual impairments in patients with blast-related traumatic

835 brain injury: Effect of dual sensory impairment on functional independence measure. $J$

836 Rehabil Res Dev 46: 819-826, 2009.

837 Liberman MC. Noise-induced and age-related hearing loss: New perspectives and

838 potential therapies. F1000Research 6: 1-11, 2017.

839 Liégeois-Chauvel C, Musolino A, Badier JM, Marquis P, Chauvel P. Evoked

840 potentials recorded from the auditory cortex in man: evaluation and topography of the 
841 middle latency components. Electroencephalogr Clin Neurophysiol Evoked Potentials

842 92: 204-214, 1994.

843 Luo H, Pace E, Zhang X, Zhang J. Blast-Induced tinnitus and spontaneous firing

844 changes in the rat dorsal cochlear nucleus. J Neurosci Res 92: 1466-1477, 2014a.

845 Luo H, Pace E, Zhang X, Zhang J. Blast-induced tinnitus and spontaneous activity

846 changes in the rat inferior colliculus. Neurosci Lett 580: 47-51, 2014b.

847 Mahmood G, Mei Z, Hojjat H, Pace E, Kallakuri S, Zhang JS. Therapeutic effect of

848 sildenafil on blast-induced tinnitus and auditory impairment. Neuroscience 269:

$849 \quad 367-382,2014$.

850 Mao JC, Pace E, Pierozynski P, Kou Z, Shen Y, Vandevord P, Haacke EM, Zhang

$851 \mathbf{X}$, Zhang J. Blast-induced tinnitus and hearing loss in rats: Behavioral and imaging

852 assays. J Neurotrauma 29: 430-444, 2012.

853 Masri S, Zhang LS, Luo H, Pace E, Zhang J, Bao S. Blast Exposure Disrupts the

854 Tonotopic Frequency Map in the Primary Auditory Cortex. Neuroscience 379:

$855 \quad 428-434,2018$.

856 McGee T, Kraus N. Auditory development reflected by middle latency response. Ear

857 Hear 17: 419-429, 1996.

858 McGee T, Kraus N, Comperatore C, Nicol T. Subcortical and cortical components of

859 the MLR generating system. Brain Res 544: 211-220, 1991.

860 McGee T, Kraus N, Littman T, Nicol T. Contributions of medial geniculate body

861 subdivisions to the middle latency response. Hear Res 61: 147-154, 1992.

862 Meehan A, Hebert D, Deru K, Weaver LK. Longitudinal study of hyperbaric oxygen 
863 intervention on balance and affective symptoms in military service members with

864 persistent post-concussive symptoms. J Vestib Res Equilib Orientat 29: 205-219,

8652019.

866 Musiek F, Nagle S. The middle latency response: A review of findings in various

867 central nervous system lesions. J. Am. Acad. Audiol. 29American Academy of

868 Audiology: 855-867, 2018.

869 Parthasarathy A, Bartlett E. Two-channel recording of auditory-evoked potentials to

870 detect age-related deficits in temporal processing. Hear Res 289: 52-62, 2012.

871 Parthasarathy A, Bartlett EL. Age-related auditory deficits in temporal processing in

872 F-344 rats. Neuroscience 192: 619-630, 2011.

873 Parthasarathy A, Cunningham PA, Bartlett EL. Age-related differences in auditory

874 processing as assessed by amplitude-modulation following responses in quiet and in

875 noise. Front Aging Neurosci 2: 3389, 2010.

876 Parthasarathy A, Datta J, Torres JAL, Hopkins C, Bartlett EL. Age-related

877 changes in the relationship between auditory brainstem responses and

878 envelope-following responses. JARO - J Assoc Res Otolaryngol 15: 649-661, 2014.

879 Parthasarathy A, Kujawa SG. Synaptopathy in the aging cochlea: Characterizing

880 early-neural deficits in auditory temporal envelope processing. J Neurosci 38:

$881 \quad 7108-7119,2018$.

882 Patterson JH, Hamernik RP. Blast overpressure induced structural and functional

883 changes in the auditory system. 1997.

884 Peter V, Wong K, Narne VK, Sharma M, Purdy SC, McMahon C. Assessing 
885

886

spectral and temporal processing in children and adults using Temporal Modulation Transfer Function (TMTF), Iterated Ripple Noise (IRN) perception, and Spectral Ripple Discrimination (SRD). J Am Acad Audiol 25: 210-218, 2014.

Phillips DJ, Schei JL, Meighan PC, Rector DM. State-Dependent Changes in Cortical Gain Control as Measured by Auditory Evoked Responses to Varying Intensity Stimuli. Sleep 34: 1527-1537, 2011.

Plack CJ, Barker D, Prendergast G. Perceptual consequences of "hidden" hearing loss. Trends Hear 18: 233121651455062, 2014.

Rabang CF, Parthasarathy A, Venkataraman Y, Fisher ZL, Gardner SM, Bartlett

EL. A computational model of inferior colliculus responses to amplitude modulated sounds in young and aged rats. Front Neural Circuits 6: 77, 2012.

Race N, Lai J, Shi R, Bartlett EL. Differences in postinjury auditory system pathophysiology after mild blast and nonblast acute acoustic trauma. J Neurophysiol 118: 782-799, 2017.

Rafaels K, "Dale" Bass CR, Salzar RS, Panzer MB, Woods W, Feldman S, Cummings T, Capehart B. Survival Risk Assessment for Primary Blast Exposures to the Head. J Neurotrauma 28: 2319-2328, 2011.

Remenschneider AK, Lookabaugh S, Aliphas A, Brodsky JR, Devaiah AK, Dagher W, Grundfast KM, Heman-Ackah SE, Rubin S, Sillman J, Tsai AC, Vecchiotti M, Kujawa SG, Lee DJ, Quesnel AM. Otologic outcomes after blast injury: The Boston Marathon experience. Otol Neurotol 35: 1825-1834, 2014.

Ritenour AE, Wickley A, Ritenour JS, Kriete BR, Blackbourne LH, Holcomb JB, 
907 Wade CE. Tympanic membrane perforation and hearing loss from blast overpressure

908 in Operation Enduring Freedom and Operation Iraqi Freedom wounded. J Trauma 64,

9092008.

910 Rosen S. Temporal information in speech: acoustic, auditory and linguistic aspects.

911 Philos. Trans. R. Soc. Lond. B. Biol. Sci. 336The Royal Society London: 367-373,

9121992.

913 Säljö A, Mayorga M, Bolouri H, Svensson B, Hamberger A. Mechanisms and

914 pathophysiology of the low-level blast brain injury in animal models. Neuroimage 54:

915 S83-S88, 2011.

916 Saunders GH, Frederick MT, Arnold M, Silverman S, Chisolm TH, Myers P.

917 Auditory difficulties in blast-exposed veterans with clinically normal hearing. J Rehabil

918 Res Dev 52: 343-360, 2015.

919 Simpson G V., Knight RT, Brailowsky S, Prospero-Garcia O, Scabini D. Altered

920 peripheral and brainstem auditory function in aged rats. Brain Res 348: 28-35, 1985.

921 Simpson MIG, Prendergast G. Auditory magnetic evoked responses. In: Handbook

922 of Clinical Neurophysiology. 2013, p. 253-270.

923 Skoe E, Kraus N. Auditory Brain Stem Response to Complex Sounds: A Tutorial. Ear 924 Hear 31: 302-324, 2010.

925 Song S, Race NS, Kim A, Zhang T, Shi R, Ziaie B. A Wireless Intracranial Brain

926 Deformation Sensing System for Blast-Induced Traumatic Brain Injury. Sci Rep 5:

$927 \quad 1-10,2015$.

928 Šuta D, Rybalko N, Pelánová J, Popelář J, Syka J. Age-related changes in auditory 
929 temporal processing in the rat. Exp Gerontol 46: 739-746, 2011.

930 Swaminathan J, Krishnan A, Gandour JT. Pitch encoding in speech and

931 nonspeech contexts in the human auditory brainstem. Neuroreport 19: 1163-1167,

9322008.

933 Thompson W, Marozeau J. Auditory Stream Segregation: Boundaries. In: Music in

934 the Social and Behavioral Sciences: An Encyclopedia. 2014.

935 Tichko P, Skoe E. Frequency-dependent fine structure in the frequency-following

936 response: The byproduct of multiple generators. Hear Res 348: 1-15, 2017.

937 Tukey JW. Comparing Individual Means in the Analysis of Variance. Biometrics 5: 99, 9381949.

939 Unnikrishnan G, Mao H, Sundaramurthy A, Bell ED, Yeoh S, Monson K, Reifman

940 J. A 3-D Rat Brain Model for Blast-Wave Exposure: Effects of Brain Vasculature and

941 Material Properties. Ann Biomed Eng 47: 2033-2044, 2019.

942 Valderrama JT, Beach EF, Yeend I, Sharma M, Van Dun B, Dillon H. Effects of

943 lifetime noise exposure on the middle-age human auditory brainstem response,

944 tinnitus and speech-in-noise intelligibility. Hear Res 365: 36-48, 2018.

945 Viana LM, O’Malley JT, Burgess BJ, Jones DD, Oliveira CACP, Santos F,

946 Merchant SN, Liberman LD, Liberman MC. Cochlear neuropathy in human

947 presbycusis: Confocal analysis of hidden hearing loss in post-mortem tissue. Hear

$948 \quad$ Res 327: 78-88, 2015.

949 Wagner L, Plontke SK, Rahne T. Perception of Iterated Rippled Noise Periodicity in

950 Cochlear Implant Users. Audiol Neurotol 22: 104-115, 2017. 
951 Walls MK, Race N, Zheng L, Vega-Alvarez SM, Acosta G, Park J, Shi R. Structural

952 and biochemical abnormalities in the absence of acute deficits in mild primary

953 blast-induced head trauma. J Neurosurg 124: 675-686, 2016.

954 Walton JP. Timing is everything: Temporal processing deficits in the aged auditory

955 brainstem. Hear Res 264: 63-69, 2010.

956 Wang H, Turner JG, Ling L, Parrish JL, Hughes LF, Caspary DM. Age-related

957 changes in glycine receptor subunit composition and binding in dorsal cochlear

958 nucleus. Neuroscience 160: 227-239, 2009.

959 Wang X, Lu T, Bendor D, Bartlett E. Neural coding of temporal information in

960 auditory thalamus and cortex. Neuroscience 154: 294-303, 2008.

961 Yost WA. Pitch of iterated rippled noise. J Acoust Soc Am 100: 511-518, 1996a.

962 Yost WA. Pitch strength of iterated rippled noise. J Acoust Soc Am 100: 3329-3335,

$9631996 b$.

964

965 
Fig 1. Auditory evoked potential experiment setup and examples of $A B R$ waveforms. A) Electrode placement and channel configuration of the study's auditory evoked potential experiment. B) Examples of ABR waveforms of a pre-exposure animal, at $80 \mathrm{~dB}$ SPL and $30 \mathrm{~dB}$ SL, with relevant wave peaks labeled. The waves for which amplitudes are measured are labeled with a black triangle.

Fig 2. ABR threshold changes of Blast $(\mathrm{N}=10)$ and Sham $(\mathrm{N}=6)$ rats during the first two months post-exposure. Blast animals demonstrated drastic increases (worse) of Click, $8 \mathrm{kHz}$, and $16 \mathrm{kHz}$ thresholds (red lines) post-exposure as opposed to Sham animals (blue lines). Significant main effects $(p \leq 0.001)$ of Groups and Group*Time interactions were observed in all carriers. Significant Simple Main Effect of single time points observed in various carriers throughout the two months. For subsequent figures, red lines will denote blast-exposed animals, and blue lines will denote sham-exposed animals. Asterisks indicate time points where significant Simple Main Effects of Group was demonstrated (Supp. Table 1):

${ }^{* * *}$ Blast threshold significantly higher than Sham in Click, $8 \mathrm{kHz}$, and $16 \mathrm{kHz}, \mathrm{p}<0.05$;

${ }^{* * B}$ last threshold significantly higher only in Click and $16 \mathrm{kHz}$;

*Blast threshold significantly higher only in Click.

Fig 3. ABR wave I, III, and V amplitudes of Blast $(\mathrm{N}=10)$ and Sham $(\mathrm{N}=6)$ rats during the first two months post-exposure expose persistent blast-induced differences at $80 \mathrm{~dB}$ SPL. Significant main Group ${ }^{*}$ Time interaction effects ( $\left.p \leq 0.001\right)$ 
observed in waves I (left column), III (center column), and V (right column) for all carriers: A) Click ABR; B) $8 \mathrm{kHz} \mathrm{ABR;} \mathrm{C)} 16 \mathrm{kHz}$ ABR. Click ABR revealed blast-induced reduction of $A B R$ wave amplitudes to a greater degree than both tone ABRs. Later waves (Wave III and V) showed earlier recovery in Blast animals.

*Significant Simple Main Effect of Group in ABR Wave Amplitudes, $p<0.05$.

Fig 4. ABR wave $\mathrm{I}$, III, and $\mathrm{V}$ amplitudes of Blast $(\mathrm{N}=10)$ and Sham $(\mathrm{N}=6)$ rats during the first two months post-exposure at $30 \mathrm{~dB}$ SL. Similar format to Fig. 3 . Significant main Group ${ }^{*} T i m e$ interaction effects only observed with Click ABR waves (Wave I: $p=0.016$; Wave III: $p=0.04$; Wave V: $p=0.003$ ) A) Click ABR; B) 8 kHz ABR; C) $16 \mathrm{kHz}$ ABR.

*Significant Simple Main Effect of Group in ABR Wave Amplitudes, $p<0.05$.

Fig 5. MLR waveforms and peak amplitudes of Blast $(\mathrm{N}=8)$ and $\mathrm{Sham}(\mathrm{N}=6)$ rats during the first two months post-exposure at $80 \mathrm{~dB}$ SPL and at $30 \mathrm{~dB} \mathrm{SL}$ (Thresh + $30 \mathrm{~dB}$ ). Grand average traces of Click MLR waveforms at $80 \mathrm{~dB}$ SPL: A) Blast, pre-blast to day 7. Arrowheads indicate measured peaks in E-H; B) Sham, pre-blast to day 7; C) Blast, day 10 to day 60 ; D) Sham, day 10 to day 60. Normalized Click MLR wave amplitudes over time: E) Blast, 80 dB SPL; F) Sham, 80 dB SPL; G) Blast, 30 dB SL; H) Blast, 30 dB SL.

*Significant difference in normalized wave P1, N1 and P2 amplitudes compared to pre-exposure, $p<0.05$. 
1010 †Significant difference in normalized wave N1 amplitudes only, $p<0.05$.

$1011 \quad \ddagger$ Significant difference in normalized wave N1 and P2 amplitude, $\mathrm{p}<0.05$.

1012

1013 Fig 6. AM depth stimuli and EFR responses from Blast $(\mathrm{N}=10)$ and Sham $(\mathrm{N}=6)$

1014 rats during the first two months post-exposure at $\mathbf{3 0} \mathrm{dB}$ above threshold, in

1015 quiet. A) AM depth stimulus waveforms at $100 \%$ and $50 \%$ modulation depths; B)

1016 nSAM FFT amplitudes at $10 \mathrm{~Hz}$ (left), $45 \mathrm{~Hz}$ (center), and $256 \mathrm{~Hz}$ (right). Significant

1017 Group effect at $45 \mathrm{~Hz}(p=0.007)$; Similar format in C and D. C) SAM $8 \mathrm{kHz}$ FFT

1018 amplitudes at $45 \mathrm{~Hz}$ show a steady yet insignificant increase in later short-term (day

1019 7-14); D) SAM 16k FFT amplitudes found no significant Group effect.

$1020{ }^{*}$ Significant Simple Main Effect of Group in FFT Amplitudes in both $100 \%$ depth and

$102150 \%$ depth

1022 * Significant Simple Main Effect of Group in FFT Amplitudes only in 100\% depth

1023

1024

Fig 7. AM noise stimuli and EFR responses from Blast $(\mathrm{N}=10)$ and Sham $(\mathrm{N}=6)$

1025 rats during the first two months post-exposure at $\mathbf{3 0} \mathbf{~ d B}$ above threshold,

1026 modulation depth $\mathbf{1 0 0} \%$. A) AM noise stimulus composition and waveform. B)

1027 Amplitude modulated noise carrier. FFT amplitudes at signal modulation frequency in

1028 quiet and with $71 \mathrm{~Hz}$ AM noise masker level of 20SNR or 0SNR (equal) show

1029 significant Noise * Group effect for: B) nSAM noise at $45 \mathrm{~Hz}(p=0.011)$ modulation

1030 frequency; C) SAM $8 \mathrm{kHz}$ noise at $10 \mathrm{~Hz}(\mathrm{p}=0.001)$ and $45 \mathrm{~Hz}(\mathrm{p}=0.015)$ modulation

1031 frequency. 
1032 * Significant Simple Main Effect of Group

1033

1034 Fig 8. IRN Chinese Tone stimuli and responses from Blast $(\mathbf{N}=8)$ and Sham

1035 ( $N=6)$ rats during the first two months post-exposure at $30 \mathrm{~dB}$ above threshold,

103632 iterations. A) Example waveform and spectrogram of IRN Tone 2 stimulus; B)

1037 Examples of Peak Frequency of IRN Evoked Potential in Pre-blast (score: Tone

$10382=36 / 51$, Tone 4=39/51) and Post-blast Brain (day 10 post-blast, score: Tone

$10392=21 / 51$, Tone 4=18/51) from an individual animal; C) Significant effect of Group $\left({ }^{*}\right)$

1040 was seen in IRN Tone 2 (top, $p=0.026$ ) and Tone 4 (bottom, $p=0.029$ ) pitch-tracking

1041 score, though Simple Main Effect of is limited for individual time points; D)

1042 Cross-correlation of post-blast IRN responses to corresponding pre-blast responses.

1043 Significant differences $\left(^{*}\right)$ in correlation coefficients to pre-blast responses between

1044 Blast and Sham were observed in two waves: day 1-10, and day $30(p<0.05$, paired

1045 sign-rank).

1046

1047 Fig 9. Pitch tracking scores of responses to IRN Tone 2 stimuli with pitch

1048 salience controlled by altering iteration number at different time points, at $\mathbf{3 0}$

1049 dB above threshold. Though the effect of Iterations on pitch-tracking score was

1050 significant $(p<0.001)$, no significant Iteration * Group interaction was observed.

1052 Table 1. Summary of $80 \mathrm{~dB}$ SPL ABR Wave I, III and V repeated measure ABR

1053 statistics. 
1055 Table 2. Summary of $\mathbf{3 0} \mathrm{dB}$ SL ABR Wave I, III and V repeated measure ABR

1056 statistics.

Table 3. Simple main effects of Group on ABR wave amplitudes over time.

Post-blast $\mathrm{ABR}$ amplitudes of Blast $(\mathrm{N}=10)$ and Sham $(\mathrm{N}=6)$ groups are compared

using rmANOVA at each time point recorded. A $p<0.05$ showed significant simple

1061

main effect of Group at that time point.

1062

Table 4. Summary of post hoc tests against pre-blast ABR amplitudes.

Post-blast ABR amplitudes of Blast $(\mathrm{N}=10)$ and Sham $(\mathrm{N}=6)$ are compared against

pre-blast amplitudes of the same group to show blast impact and recovery.

1066

Table 5. Simple main effects of Group on click MLR wave amplitudes at $80 \mathrm{~dB}$

SPL over time. Post-blast click MLR amplitudes of Blast $(\mathrm{N}=8)$ and Sham $(\mathrm{N}=6)$

groups at $80 \mathrm{~dB}$ SPL are compared using rmANOVA at each time point recorded. A 
1072 Table 1

\begin{tabular}{|c|c|c|c|c|c|c|}
\hline \multicolumn{3}{|c|}{ 80dB SPL ABR } & \multirow{2}{*}{$\begin{array}{l}\text { df } \\
4.163\end{array}$} & \multirow{2}{*}{$\begin{array}{l}\mathbf{F} \\
9.980\end{array}$} & \multirow{2}{*}{$\begin{array}{l}p \\
<.001\end{array}$} & \multirow{2}{*}{$\begin{array}{l}\eta^{2} \mathbf{p} \\
0.416\end{array}$} \\
\hline Click & Wave I & Time & & & & \\
\hline & & Group & 1.000 & 23.080 & $<.001$ & 0.622 \\
\hline & & Time * Group & 4.163 & 11.685 & $<.001$ & 0.455 \\
\hline & Wave & Time & 3.641 & 11.065 & $<.001$ & 0.441 \\
\hline & III & & & & & \\
\hline & & Group & 1.000 & 17.207 & $<.001$ & 0.551 \\
\hline & & Time * Group & 3.641 & 8.871 & $<.001$ & 0.388 \\
\hline & Wave V & Time & 4.000 & 14.134 & $<.001$ & 0.502 \\
\hline & & Group & 1.000 & 23.203 & $<.001$ & 0.624 \\
\hline & & Time * Group & 4.000 & 10.990 & $<.001$ & 0.440 \\
\hline \multirow[t]{9}{*}{$8 \mathrm{kHz}$} & Wave I & Time & 4.413 & 8.102 & $<.001$ & 0.367 \\
\hline & & Group & 1.000 & 14.409 & 0.002 & 0.507 \\
\hline & & Time * Group & 4.413 & 11.760 & $<.001$ & 0.457 \\
\hline & Wave & Time & 3.378 & 14.084 & $<.001$ & 0.501 \\
\hline & & & & & 0025 & 0309 \\
\hline & & Group & 3.378 & $\begin{array}{l}0 .<00 \\
13826\end{array}$ & $<.001$ & 0.497 \\
\hline & Wave V & Time & 3.908 & 8.545 & $<.001$ & 0.379 \\
\hline & & Group & 1.000 & 9.859 & 0.007 & 0.413 \\
\hline & & Time * Group & 3.908 & 9.346 & $<.001$ & 0.400 \\
\hline \multirow[t]{10}{*}{$16 \mathrm{kHz}$} & Wave I & Time & 3.534 & 9.845 & $<.001$ & 0.413 \\
\hline & & Group & 1.000 & 27.486 & $<.001$ & 0.663 \\
\hline & & Time * Group & 3.534 & 14.328 & $<.001$ & 0.506 \\
\hline & Wave & Time & 3.055 & 9.845 & $<.001$ & 0.413 \\
\hline & III & & & & & \\
\hline & & Group & 1.000 & 13.048 & 0.003 & 0.482 \\
\hline & & Time * Group & 3.055 & 14.328 & $<.001$ & 0.506 \\
\hline & Wave V & Time & 3.933 & 8.838 & $<.001$ & 0.387 \\
\hline & & Group & 1.000 & 20.528 & $<.001$ & 0.595 \\
\hline & & Time * Group & 3.933 & 10.066 & $<.001$ & 0.418 \\
\hline
\end{tabular}


1075 Table 2

\begin{tabular}{|c|c|c|c|c|c|c|}
\hline \multicolumn{3}{|c|}{ 30dB SL ABR } & \multirow{2}{*}{$\frac{\text { df }}{4.360}$} & \multirow{2}{*}{$\begin{array}{l}\mathbf{F} \\
2.554\end{array}$} & \multirow{2}{*}{$\frac{p}{0.043}$} & \multirow{2}{*}{$\frac{\eta_{p}^{2}}{0.154}$} \\
\hline Click & Wave I & Time & & & & \\
\hline & & Group & 1.000 & 3.637 & 0.077 & 0.206 \\
\hline & & Time * Group & 4.360 & 2.630 & 0.039 & 0.158 \\
\hline & Wave III & Time & 3.878 & 2.544 & 0.052 & 0.154 \\
\hline & & Group & 1.000 & 1.811 & 0.200 & 0.115 \\
\hline & & Time * Group & 3,878 & 2.720 & 0.040 & 0.163 \\
\hline & Wave V & Time & 4.784 & 2.568 & 0.037 & 0.155 \\
\hline & & Group & 1.000 & 1.479 & 0.244 & 0.096 \\
\hline & & Time * Group & 4.784 & 3.429 & 0.009 & 0.197 \\
\hline \multirow[t]{9}{*}{$8 \mathrm{kHz}$} & Wave I & Time & 4.264 & 3.146 & 0.018 & 0.183 \\
\hline & & Group & 1.000 & $6.852 e--5$ & 0.994 & 0.000 \\
\hline & & Time * Group & 4.264 & 0.200 & 0.945 & 0.014 \\
\hline & Wave III & Time & 3.414 & 2.432 & 0.069 & 0.148 \\
\hline & & Group & 1.000 & 0.020 & 0.889 & 0.001 \\
\hline & & Time * Group & 3.414 & 1.184 & 0.328 & 0.078 \\
\hline & Wave V & Time & 3.912 & 1.837 & 0.136 & 0.116 \\
\hline & & Group & 1.000 & 0.361 & 0.558 & 0.025 \\
\hline & & Time * Group & 3.912 & 0.618 & 0.648 & 0.042 \\
\hline \multirow[t]{9}{*}{$16 \mathrm{kHz}$} & Wave I & Time & 4.469 & 2.325 & 0.031 & 0.142 \\
\hline & & Group & 1.000 & 1.046 & 0.324 & 0.070 \\
\hline & & Time * Group & 4.469 & 2.381 & 0.027 & 0.145 \\
\hline & Wave III & Time & 3.160 & 0.562 & 0.651 & 0.039 \\
\hline & & Group & 1.000 & 1.149 & 0.302 & 0.076 \\
\hline & & Time * Group & 3.160 & 1.930 & 0.136 & 0.121 \\
\hline & Wave V & Time & 4.874 & 1.160 & 0.338 & 0.077 \\
\hline & & Group & 1.000 & $4.905 e \sqsupset-4$ & 0.983 & 0.000 \\
\hline & & Time * Group & 4.874 & 1.646 & 0.161 & 0.105 \\
\hline
\end{tabular}


1078 Table 3

Simple Main Effects

$80 \mathrm{~dB}$ SPL

$30 \mathrm{~dB} S L$

\begin{tabular}{|c|c|c|c|c|c|c|c|c|}
\hline & & Time & Mean square & $\mathrm{F}$ & $p$ & $\begin{array}{l}\text { Mean } \\
\text { Square }\end{array}$ & $F$ & p \\
\hline \multirow[t]{21}{*}{ Click } & \multirow[t]{7}{*}{ Wave I } & day1 & 13.942 & 31.329 & $<.001$ & 2.097 & 8.019 & 0.013 \\
\hline & & day4 & 12.438 & 30.917 & $<.001$ & 1.843 & 7.730 & 0.015 \\
\hline & & day7 & 4.081 & 18.418 & $<.001$ & 0.024 & 0.102 & 0.754 \\
\hline & & day10 & 1.601 & 7.023 & 0.019 & 0.020 & 0.127 & 0.726 \\
\hline & & day14 & 3.180 & 10.008 & 0.007 & 0.596 & 3.044 & 0.103 \\
\hline & & day30 & 1.517 & 8.285 & 0.012 & 0.184 & 1.829 & 0.198 \\
\hline & & day60 & 1.013 & 4.393 & 0.055 & 0.102 & 0.632 & 0.440 \\
\hline & \multirow[t]{7}{*}{ Wave III } & day1 & 9.708 & 30.148 & $<.001$ & 1.977 & 6.629 & 0.022 \\
\hline & & day4 & 5.754 & 23.070 & $<.001$ & 0.692 & 3.416 & 0.086 \\
\hline & & day7 & 3.725 & 33.967 & $<.001$ & 0.470 & 3.917 & 0.068 \\
\hline & & day10 & 1.690 & 11.712 & 0.004 & 0.093 & 0.665 & 0.429 \\
\hline & & day14 & 0.854 & 8.587 & 0.011 & 0.039 & 0.474 & 0.502 \\
\hline & & day30 & 0.634 & 4.714 & 0.048 & 0.005 & 0.088 & 0.771 \\
\hline & & day60 & 0.064 & 0.315 & 0.584 & 0.029 & 0.219 & 0.647 \\
\hline & \multirow[t]{7}{*}{ Wave V } & day1 & 17.134 & 45.066 & $<.001$ & 3.596 & 9.213 & 0.009 \\
\hline & & day4 & 14.672 & 35.376 & $<.001$ & 2.178 & 8.580 & 0.011 \\
\hline & & day7 & 4.419 & 13.382 & 0.003 & 0.056 & 0.132 & 0.722 \\
\hline & & day10 & 2.264 & 8.415 & 0.012 & 0.012 & 0.043 & 0.839 \\
\hline & & day14 & 4.709 & 16.223 & 0.001 & 0.104 & 0.347 & 0.565 \\
\hline & & day30 & 1.214 & 3.651 & 0.077 & 0.009 & 0.028 & 0.870 \\
\hline & & day60 & 0.414 & 1.155 & 0.301 & 0.002 & 0.007 & 0.934 \\
\hline \multirow[t]{18}{*}{$8 \mathrm{kHz}$} & \multirow[t]{7}{*}{ Wave I } & day1 & 7.136 & 45.959 & $<.001$ & 0.000 & 0.004 & 0.948 \\
\hline & & day4 & 6.915 & 37.954 & $<.001$ & 0.001 & 0.014 & 0.909 \\
\hline & & day7 & 1.892 & 15.704 & 0.001 & 0.017 & 0.551 & 0.470 \\
\hline & & day10 & 0.754 & 2.693 & 0.123 & 0.014 & 0.159 & 0.696 \\
\hline & & day14 & 0.803 & 4.657 & 0.049 & 0.010 & 0.096 & 0.762 \\
\hline & & day30 & 0.421 & 2.532 & 0.134 & 0.001 & 0.015 & 0.904 \\
\hline & & day60 & 0.285 & 1.562 & 0.232 & 0.006 & 0.450 & 0.513 \\
\hline & \multirow[t]{7}{*}{ Wave III } & day1 & 5.977 & 37.898 & $<.001$ & 0.084 & 0.838 & 0.375 \\
\hline & & day4 & 4.139 & 36.832 & $<.001$ & 0.000 & 0.000 & 0.984 \\
\hline & & day7 & 3.544 & 23.802 & $<.001$ & 0.034 & 0.703 & 0.416 \\
\hline & & day10 & 0.990 & 5.847 & 0.030 & 0.017 & 0.232 & 0.637 \\
\hline & & day14 & 0.167 & 0.851 & 0.372 & 0.055 & 1.274 & 0.278 \\
\hline & & day30 & 0.022 & 0.131 & 0.722 & 0.041 & 0.301 & 0.592 \\
\hline & & day60 & 0.167 & 0.640 & 0.437 & 0.062 & 1.420 & 0.253 \\
\hline & \multirow[t]{4}{*}{ Wave V } & day1 & 6.374 & 100.269 & $<.001$ & 0.020 & 0.135 & 0.719 \\
\hline & & day4 & 4.459 & 28.229 & $<.001$ & 0.005 & 0.165 & 0.691 \\
\hline & & day7 & 1.580 & 11.078 & 0.005 & 0.129 & 3.798 & 0.072 \\
\hline & & day10 & 0.392 & 2.043 & 0.175 & 0.104 & 1.256 & 0.281 \\
\hline
\end{tabular}




\begin{tabular}{|c|c|c|c|c|c|c|c|}
\hline & day14 & 0.449 & 3.269 & 0.092 & 0.001 & 0.010 & 0.924 \\
\hline & day30 & 0.006 & 0.026 & 0.875 & 0.018 & 0.149 & 0.705 \\
\hline & day60 & 0.017 & 0.060 & 0.811 & 0.007 & 0.187 & 0.672 \\
\hline \multirow{7}{*}{$\begin{array}{l}16 \\
\mathrm{kHz}\end{array}$} & day1 & 5.090 & 40.130 & $<.001$ & 0.205 & 2.470 & 0.138 \\
\hline & day4 & 5.910 & 61.374 & $<.001$ & 0.026 & 0.827 & 0.378 \\
\hline & day7 & 2.397 & 29.278 & $<.001$ & 0.090 & 2.321 & 0.150 \\
\hline & day10 & 0.723 & 4.602 & 0.050 & 0.009 & 0.305 & 0.590 \\
\hline & day14 & 1.766 & 24.888 & $<.001$ & 0.009 & 0.153 & 0.701 \\
\hline & day30 & 0.515 & 6.551 & 0.023 & 0.000 & 0.000 & 0.992 \\
\hline & day60 & 0.205 & 2.242 & 0.156 & 0.022 & 1.009 & 0.332 \\
\hline \multirow[t]{7}{*}{ Wave III } & day1 & 3.592 & 39.592 & $<.001$ & 0.205 & 2.470 & 0.138 \\
\hline & day4 & 2.919 & 38.728 & $<.001$ & 0.026 & 0.827 & 0.378 \\
\hline & day7 & 2.507 & 35.072 & $<.001$ & 0.090 & 2.321 & 0.150 \\
\hline & day10 & 0.965 & 11.997 & 0.004 & 0.009 & 0.305 & 0.590 \\
\hline & day14 & 0.676 & 8.374 & 0.012 & 0.009 & 0.153 & 0.701 \\
\hline & day30 & 0.253 & 3.337 & 0.089 & 0.000 & 0.000 & 0.992 \\
\hline & day60 & 0.006 & 0.056 & 0.816 & 0.022 & 1.009 & 0.332 \\
\hline \multirow[t]{7}{*}{ Wave V } & day1 & 4.772 & 37.802 & $<.001$ & 0.118 & 1.617 & 0.224 \\
\hline & day4 & 3.414 & 44.163 & $<.001$ & 0.000 & 0.005 & 0.945 \\
\hline & day7 & 2.150 & 21.095 & $<.001$ & 0.066 & 1.575 & 0.230 \\
\hline & day10 & 0.902 & 7.214 & 0.018 & 0.000 & 0.002 & 0.961 \\
\hline & day14 & 1.283 & 15.210 & 0.002 & 0.017 & 0.336 & 0.571 \\
\hline & day30 & 0.100 & 0.888 & 0.362 & 0.103 & 1.301 & 0.273 \\
\hline & day60 & 0.019 & 0.293 & 0.597 & 0.079 & 1.541 & 0.235 \\
\hline
\end{tabular}


80dB SPL

30dB SL

\begin{tabular}{|c|c|c|c|c|c|c|c|c|c|c|c|c|c|c|c|c|}
\hline & \multicolumn{7}{|c|}{ 80dB SPL } & \multicolumn{7}{|c|}{ 30dB SL } \\
\hline & & & day1 & day4 & day7 & day10 & day14 & day30 & day60 & day1 & day4 & day7 & day10 & day14 & day30 & day60 \\
\hline \multirow[t]{6}{*}{ Click } & \multirow[t]{2}{*}{ Wave I } & Blast & $<0.001$ & $<0.001$ & $<0.001$ & $<0.001$ & $<0.001$ & $<0.001$ & $<0.001$ & 0.001 & 0.244 & 1.000 & 1.000 & 1.000 & 0.300 & 0.808 \\
\hline & & $\begin{array}{l}\text { Sha } \\
\mathrm{m}\end{array}$ & 1.000 & 1.000 & 1.000 & 1.000 & 1.000 & 0.984 & 0.999 & 1.000 & 1.000 & 1.000 & 1.000 & 1.000 & 0.997 & 1.000 \\
\hline & \multirow[t]{2}{*}{ Wave III } & Blast & $<0.001$ & $<0.001$ & $<0.001$ & $<0.001$ & $<0.001$ & $<0.001$ & 0.002 & 0.003 & 0.015 & 0.780 & 0.285 & 0.934 & 0.528 & 0.797 \\
\hline & & $\begin{array}{l}\text { Sha } \\
\text { m }\end{array}$ & 1.000 & 0.916 & 1.000 & 0.915 & 0.902 & 0.838 & 0.600 & 1.000 & 1.000 & 1.000 & 0.966 & 0.767 & 0.854 & 0.652 \\
\hline & \multirow[t]{2}{*}{ Wave V } & Blast & $<0.001$ & $<0.001$ & $<0.001$ & $<0.001$ & $<0.001$ & $<0.001$ & $<0.001$ & 0.009 & 0.440 & 1.000 & 1.000 & 1.000 & 1.000 & 1.000 \\
\hline & & $\begin{array}{l}\text { Sha } \\
\text { m }\end{array}$ & 1.000 & 1.000 & 1.000 & 1.000 & 1.000 & 0.990 & 0.997 & 1.000 & 1.000 & 1.000 & 1.000 & 1.000 & 0.967 & 1.000 \\
\hline \multirow[t]{6}{*}{$8 \mathrm{kHz}$} & \multirow[t]{2}{*}{ Wave I } & Blast & $<0.001$ & $<0.001$ & $<0.001$ & 0.129 & 0.525 & 0.575 & 0.008 & 0.840 & 0.996 & 1.000 & 1.000 & 1.000 & 1.000 & 0.943 \\
\hline & & $\begin{array}{l}\text { Sha } \\
\text { m }\end{array}$ & 0.978 & 1.000 & 0.998 & 1.000 & 1.000 & 1.000 & 0.972 & 0.957 & 0.999 & 1.000 & 1.000 & 1.000 & 1.000 & 1.000 \\
\hline & \multirow[t]{2}{*}{ Wave III } & Blast & $<0.001$ & $<0.001$ & $<0.001$ & $<0.001$ & $<0.001$ & $<0.023$ & 0.878 & 0.998 & 1.000 & 1.000 & 1.000 & 1.000 & 1.000 & 1.000 \\
\hline & & $\begin{array}{l}\text { Sha } \\
\text { m }\end{array}$ & 1.000 & 0.996 & 1.000 & 1.000 & 0.968 & 1.000 & 0.999 & 0.995 & 1.000 & 1.000 & 0.998 & 0.932 & 1.000 & 0.932 \\
\hline & \multirow[t]{2}{*}{ Wave V } & Blast & $<0.001$ & $<0.001$ & $<0.001$ & 0.993 & 0.994 & 1.000 & 1.000 & 0.902 & 1.000 & 1.000 & 1.000 & 1.000 & 1.000 & 1.000 \\
\hline & & $\begin{array}{l}\text { sha } \\
\text { m }\end{array}$ & 1.000 & 1.000 & 0.991 & 1.000 & 1.000 & 1.000 & 0.974 & 1.000 & 1.000 & 0.998 & 1.000 & 1.000 & 1.000 & 0.999 \\
\hline
\end{tabular}




\begin{tabular}{|c|c|c|c|c|c|c|c|c|c|c|c|c|c|c|c|c|}
\hline \multirow[t]{6}{*}{$16 \mathrm{kHz}$} & \multirow[t]{2}{*}{ Wave I } & Blast & $<0.001$ & $<0.001$ & $<0.001$ & $<0.001$ & 0.050 & 0.020 & $<0.001$ & 1.000 & 1.000 & 1.000 & 1.000 & 1.000 & 1.000 & 0.999 \\
\hline & & $\begin{array}{l}\text { Sha } \\
\mathrm{m}\end{array}$ & 1.000 & 0.993 & 0.997 & 0.965 & 1.000 & 1.000 & 0.149 & 0.296 & 0.999 & 1.000 & 1.000 & 1.000 & 1.000 & 0.973 \\
\hline & \multirow[t]{2}{*}{ Wave III } & Blast & $<0.001$ & $<0.001$ & $<0.001$ & $<0.001$ & $<0.001$ & $<0.001$ & $<0.001$ & 1.000 & 1.000 & 1.000 & 1.000 & 0.993 & 1.000 & 0.930 \\
\hline & & $\begin{array}{l}\text { Sha } \\
\text { m }\end{array}$ & 1.000 & 0.990 & 0.973 & 0.534 & 0.805 & 0.838 & 0.203 & 1.000 & 0.982 & 1.000 & 0.994 & 0.880 & 0.938 & 0.890 \\
\hline & \multirow[t]{2}{*}{ Wave V } & Blast & $<0.001$ & $<0.001$ & $<0.001$ & $<0.001$ & 0.031 & 0.879 & 0.063 & 1.000 & 1.000 & 1.000 & 1.000 & 0.998 & 1.000 & 1.000 \\
\hline & & $\begin{array}{l}\text { Sha } \\
\text { m }\end{array}$ & 1.000 & 1.000 & 0.899 & 0.520 & 1.000 & 0.915 & 0.031 & 1.000 & 1.000 & 1.000 & 1.000 & 1.000 & 0.986 & 0.843 \\
\hline
\end{tabular}


Table 5

\begin{tabular}{|c|c|c|c|c|c|c|c|c|c|c|c|c|c|c|c|c|}
\hline \multirow[b]{2}{*}{ Time } & \multicolumn{4}{|c|}{ P1 } & \multicolumn{4}{|c|}{ N1 } & \multicolumn{4}{|c|}{ P2 } & \multicolumn{4}{|c|}{ N2 } \\
\hline & df & $\begin{array}{l}\text { Mean } \\
\text { Square }\end{array}$ & $\mathbf{F}$ & p & df & $\begin{array}{l}\text { Mean } \\
\text { Square }\end{array}$ & $\mathbf{F}$ & $\mathbf{p}$ & df & $\begin{array}{l}\text { Mean } \\
\text { Square }\end{array}$ & $\mathbf{F}$ & $p$ & df & $\begin{array}{l}\text { Mean } \\
\text { Square }\end{array}$ & $\mathbf{F}$ & p \\
\hline day 4 & 1 & 0.018 & 3.168 & 0.1 & 1 & 0.027 & 11.332 & 0.006 & 1 & 0.012 & 11.61 & 0.005 & 1 & 0.011 & 4.666 & 0.052 \\
\hline day7 & 1 & 0.024 & 7.68 & 0.017 & 1 & 0.002 & 3.953 & 0.07 & 1 & 0.001 & 1.446 & 0.252 & 1 & $1.950 \mathrm{e} \square-6$ & $9.167 \mathrm{e} \square-4$ & 0.976 \\
\hline day14 & 1 & 0.008 & 2.302 & 0.155 & 1 & 0.007 & 6.569 & 0.025 & 1 & 0.005 & 4.15 & 0.064 & 1 & $1.140 \mathrm{e} \square-4$ & 0.02 & 0.89 \\
\hline day30 & 1 & $9.435 \mathrm{e} \sqsupset-5$ & 0.028 & 0.869 & 1 & 0.002 & 0.514 & 0.487 & 1 & $2.632 \mathrm{e} \sqsupset-5$ & 0.011 & 0.918 & 1 & $9.054 \mathrm{e} \square-6$ & 0.002 & 0.961 \\
\hline day60 & 1 & $1.338 \mathrm{e} \sqsupset-4$ & 0.03 & 0.866 & 1 & 0.005 & 3.334 & 0.093 & 1 & 0.003 & 2.787 & 0.121 & 1 & 0.018 & 8.122 & 0.015 \\
\hline
\end{tabular}


Supplementary Table 1

\begin{tabular}{|c|c|c|c|c|c|c|c|c|c|c|c|c|}
\hline \multirow[b]{2}{*}{ Time } & \multicolumn{4}{|c|}{ Click } & \multicolumn{4}{|c|}{$8 \mathrm{kHz}$} & \multicolumn{4}{|c|}{16 kHz } \\
\hline & df & Mean Square & $\mathbf{F}$ & $\mathbf{p}$ & df & Mean Square & $\mathbf{F}$ & $\mathbf{p}$ & df & Mean Square & $\mathbf{F}$ & $\mathbf{p}$ \\
\hline day1 & 1 & 2375.104 & 42.314 & $<.001$ & 1 & 2343.75 & 23.438 & $<.001$ & 1 & 2666.667 & 16.35 & 0.001 \\
\hline day4 & 1 & 2633.438 & 61.192 & $<.001$ & 1 & 1926.667 & 98.683 & $<.001$ & 1 & 3720.937 & 40.777 & $<.001$ \\
\hline day7 & 1 & 1306.667 & 94.621 & $<.001$ & 1 & 700.417 & 19.877 & $<.001$ & 1 & 1377.604 & 21.529 & $<.001$ \\
\hline day10 & 1 & 825.104 & 37.163 & $<.001$ & 1 & 192.604 & 3.151 & 0.098 & 1 & 617.604 & 17.093 & 0.001 \\
\hline day14 & 1 & 570.417 & 46.072 & $<.001$ & 1 & 33.75 & 0.583 & 0.458 & 1 & 700.417 & 16.527 & 0.001 \\
\hline day30 & 1 & 303.75 & 10.904 & 0.005 & 1 & 23.437 & 0.228 & 0.64 & 1 & 158.438 & 2.948 & 0.108 \\
\hline day60 & 1 & 166.667 & 12.727 & 0.003 & 1 & 0.104 & 0.004 & 0.95 & 1 & 150.417 & 3.549 & 0.081 \\
\hline
\end{tabular}

Supplementary Table 1. Simple main effects of Group on Click, 8 kHz and 16 kHz ABR threshold over time. Post-blast ABR thresholds of Blast $(\mathrm{N}=10)$ and Sham $(\mathrm{N}=6)$ groups are compared using rmANOVA at each time point recorded. A p<0.05 showed significant simple main effect of Group at that time point. 
bioRxiv preprint doi: https://doi.org/10.1101/2020.11.06.371591; this version posted July 18,2021 . The copyright holder for this preprint (which was not certified by peer review) is the author/funder, who has granted bioRxiv a license to display the preprint in perpetuity. It is made available under aCC-BY-NC-ND 4.0 International license.

A

B Channel 1 (80 dB SPL)

Channel 1 (30 dB SL)
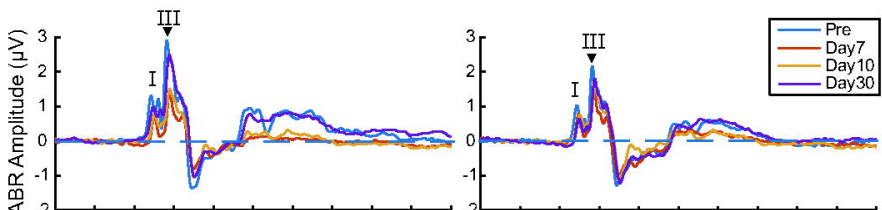

Negative

Channel 2 (80 dB SPL)
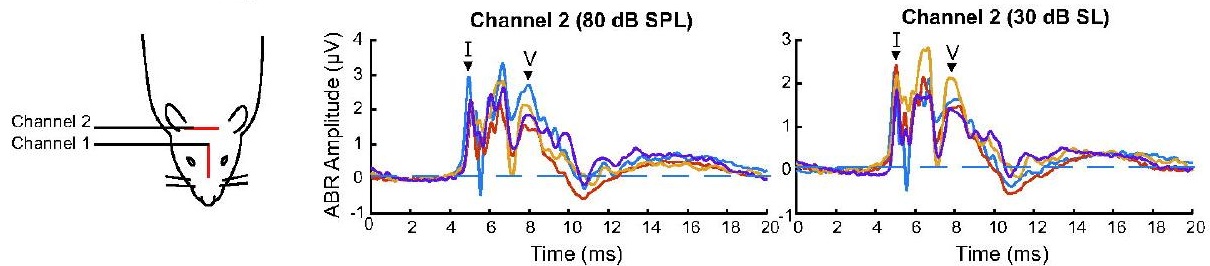

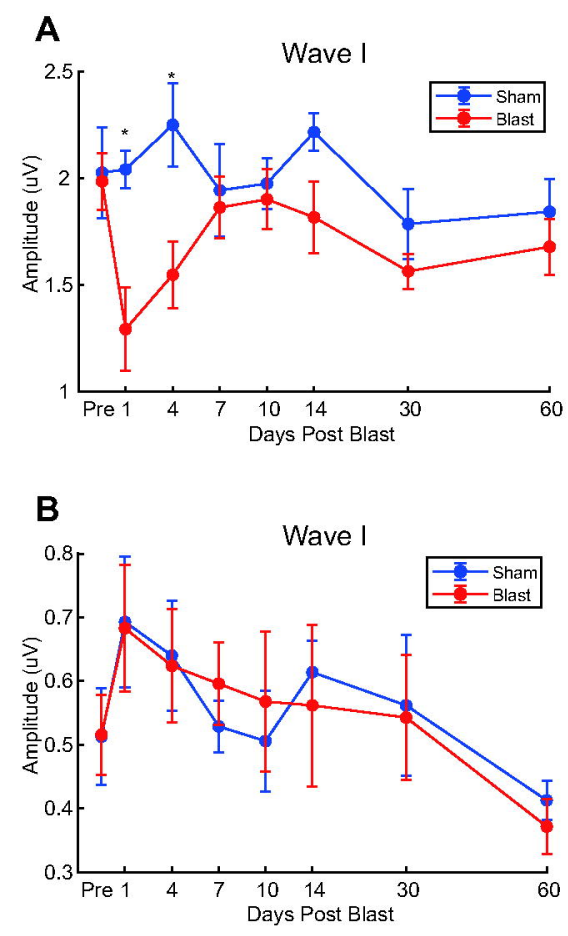

\section{C}

这

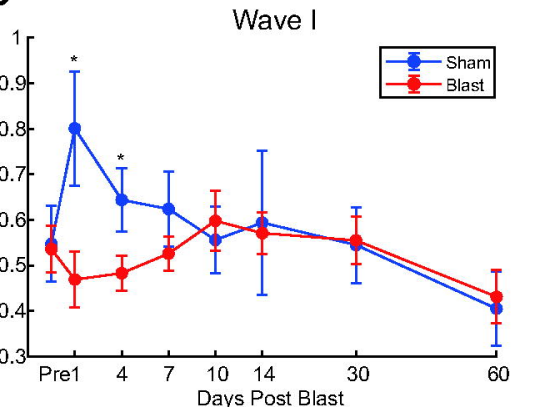

Click $30 \mathrm{~dB}$ SL

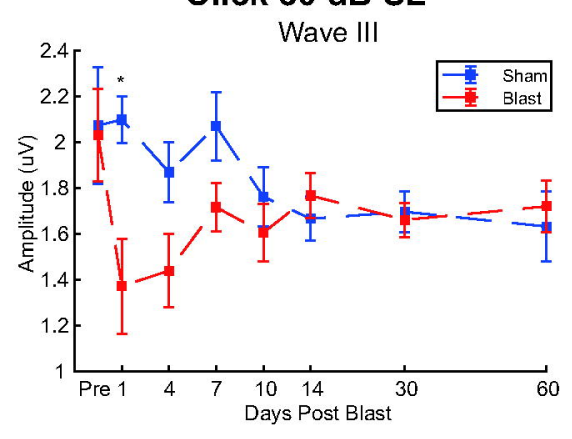

Tone 8k $30 \mathrm{~dB}$ SL
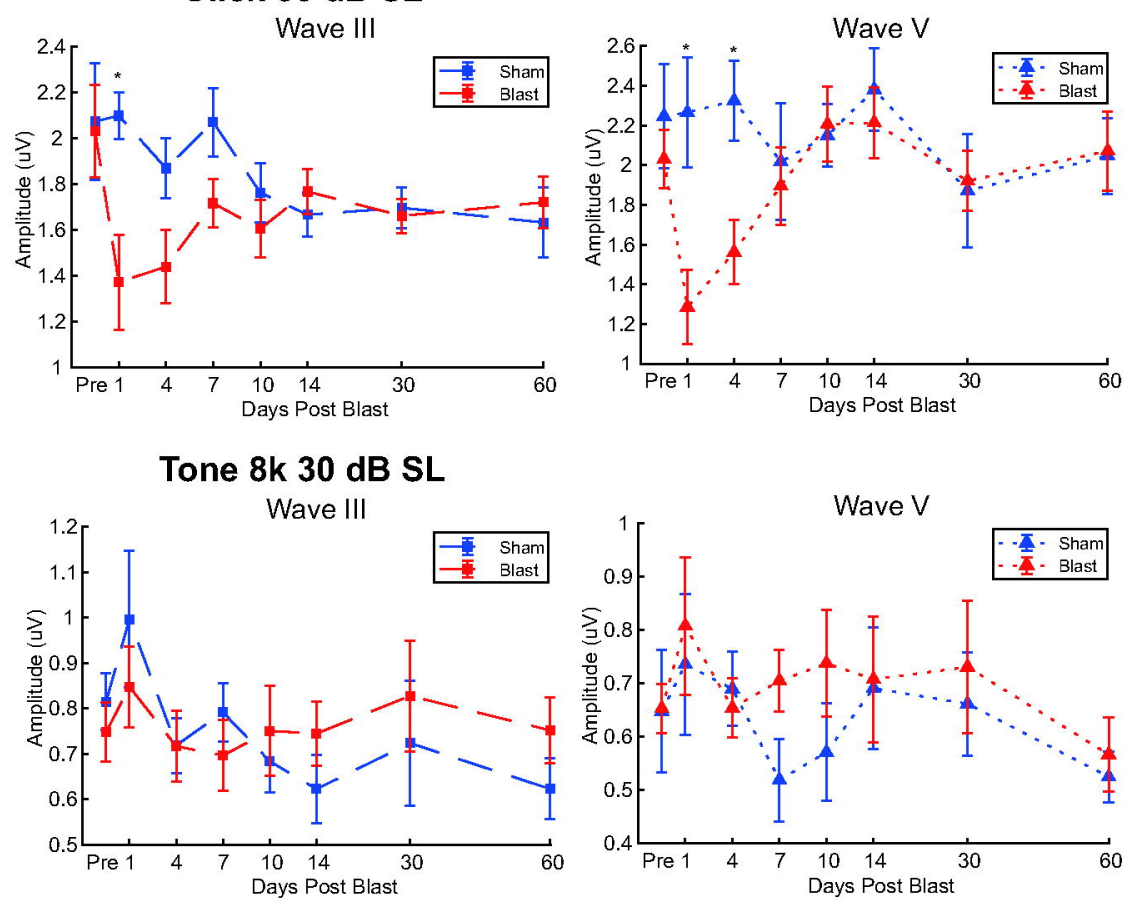

Tone $16 \mathrm{k} 30 \mathrm{~dB}$ SL

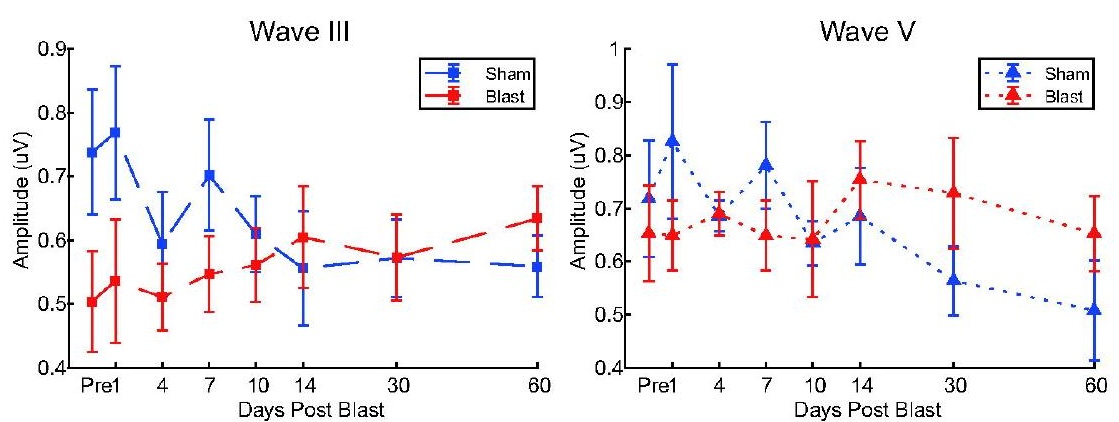


bioRxiv preprint doi: https://doi.org/10.1101/2020.11.06.371591; this version posted July 18, 2021. The copyright holder for this preprint (which

was not certified by peer review) is the author/funder, who has granted bioRxiv a license to display the preprint in perpetuity. It is made available under aCC-BY-NC-ND 4.0 International license.

Blast

A

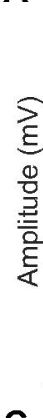

C

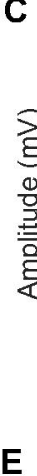

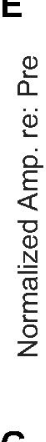

$$
\text { G }
$$

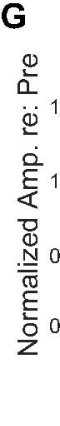
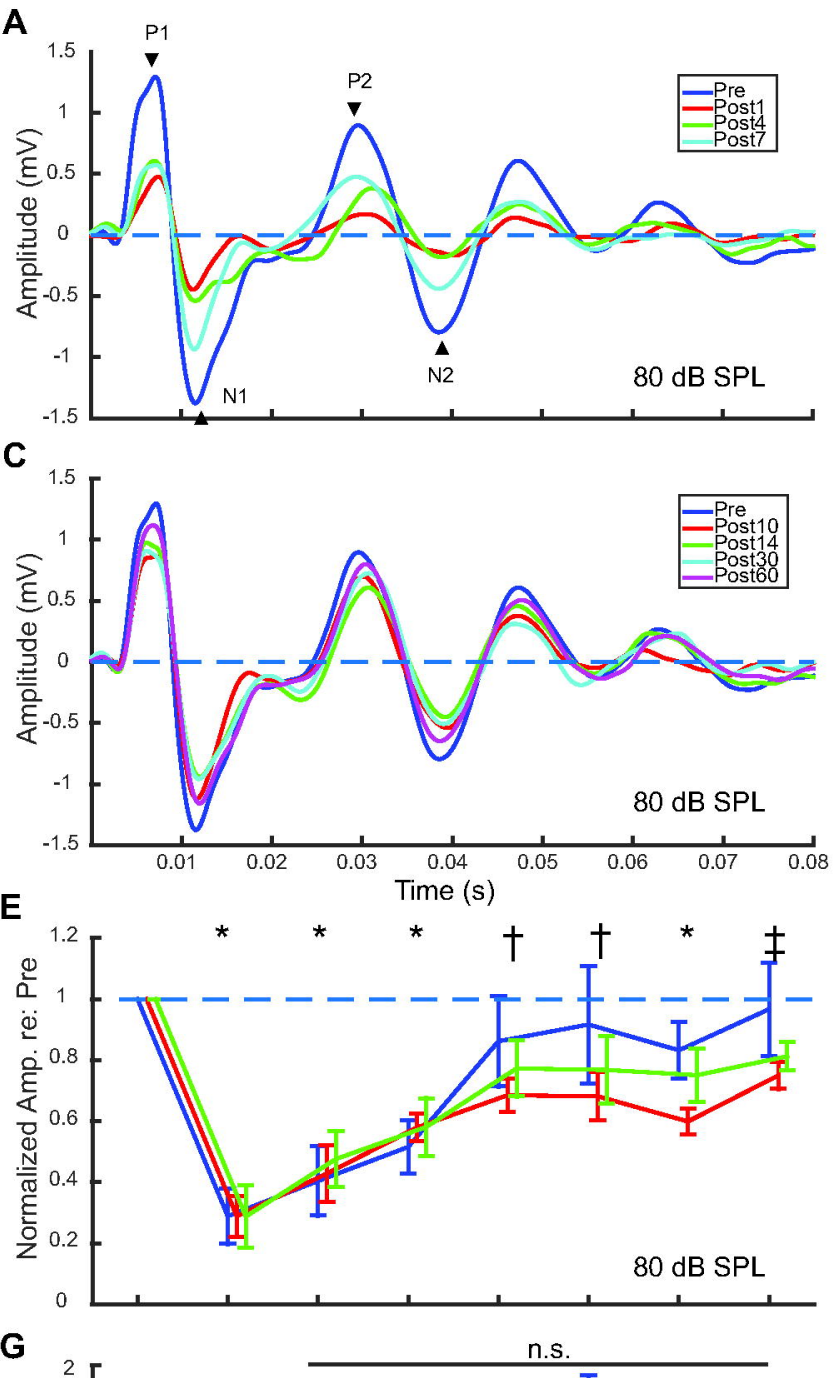

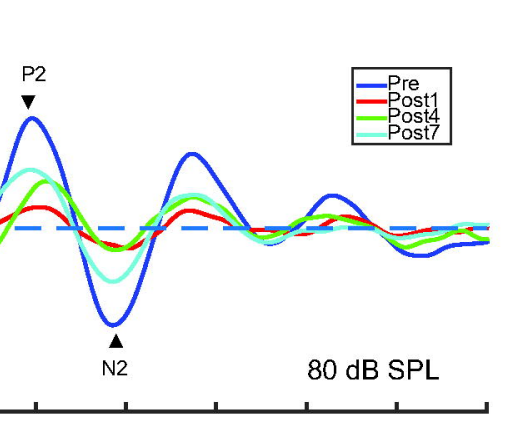

D

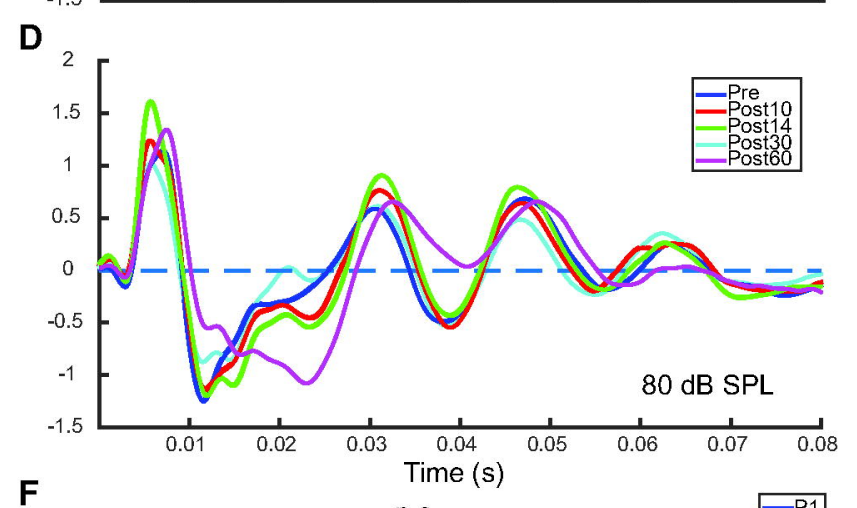

$\mathbf{F}$
Sham
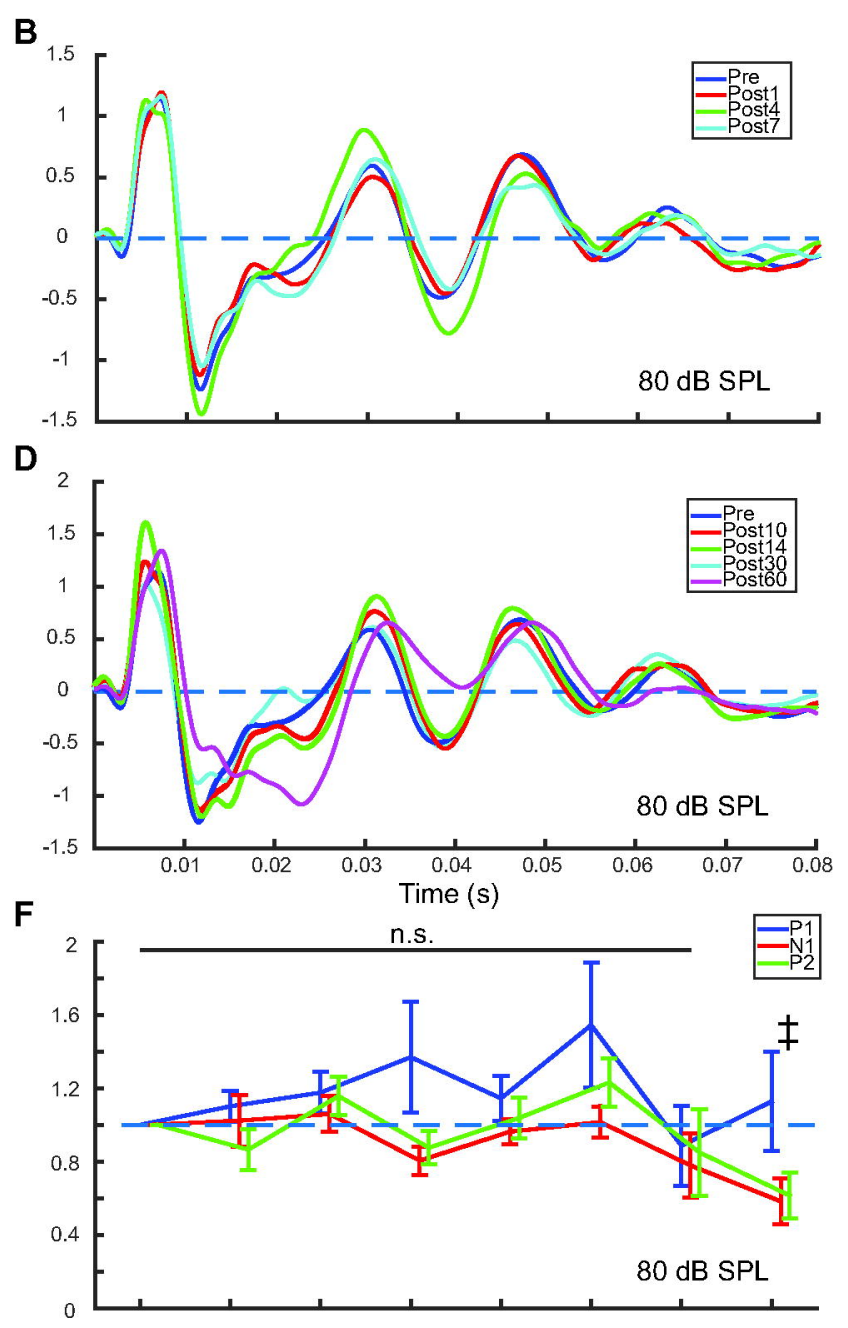

H

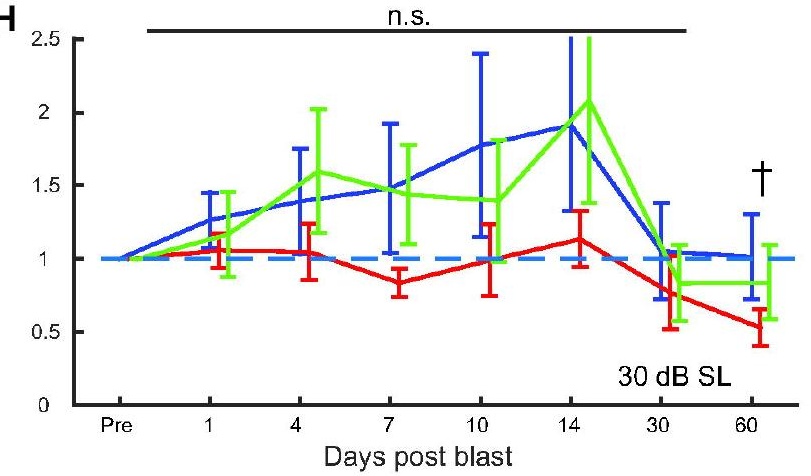


bioRxiv preprint doi: https://doi.org/10.1101/2020.11.06.371591; this version posted July 18,2021 . The copyright holder for this preprint (which was not certified by peer review) is the author/funder, who has granted bioRxiv a license to display the preprint in perpetuity. It is made available under aCC-BY-NC-ND 4.0 International license.

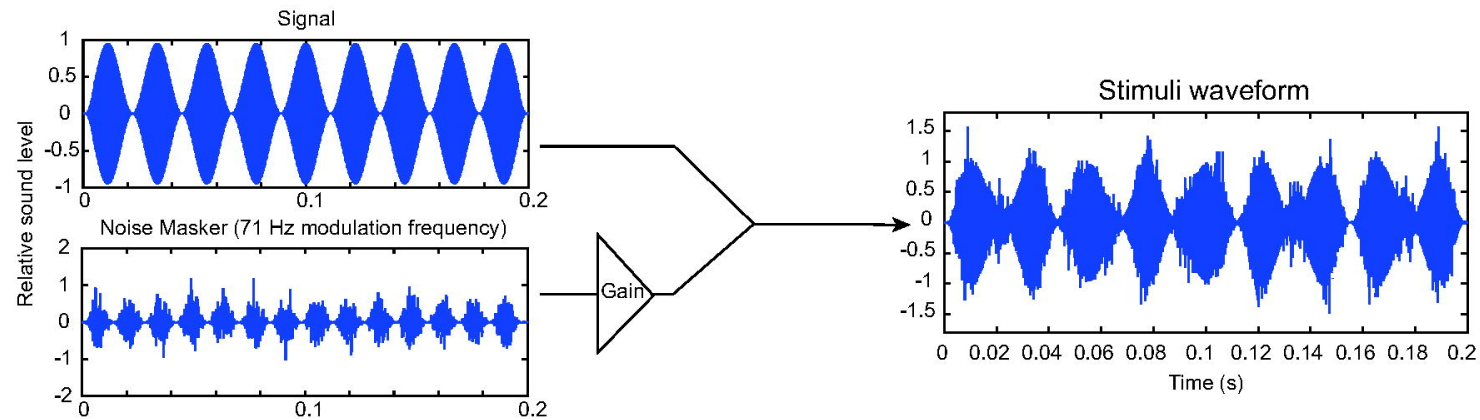

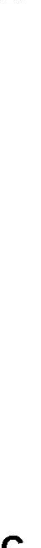

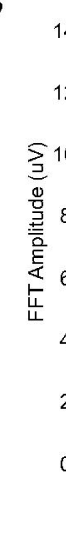

C

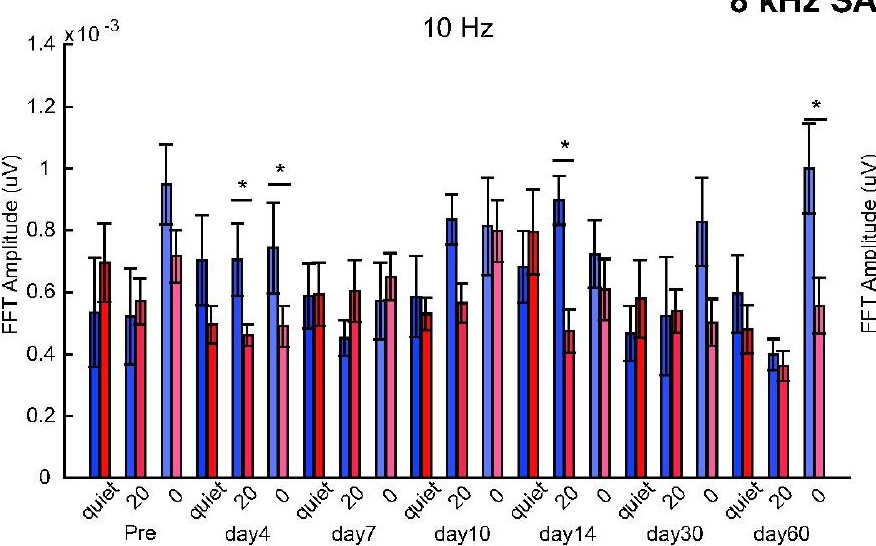


bioRxiv preprint doi: https://doi.org/10.1101/2020.11.06.371591; this version posted July 18, 2021. The copyright holder for this preprint (which was not certified by peer review) is the author/funder, who has granted bioRxiv a license to display the preprint in perpetuity. It is made available under aCC-BY-NC-ND 4.0 International license.
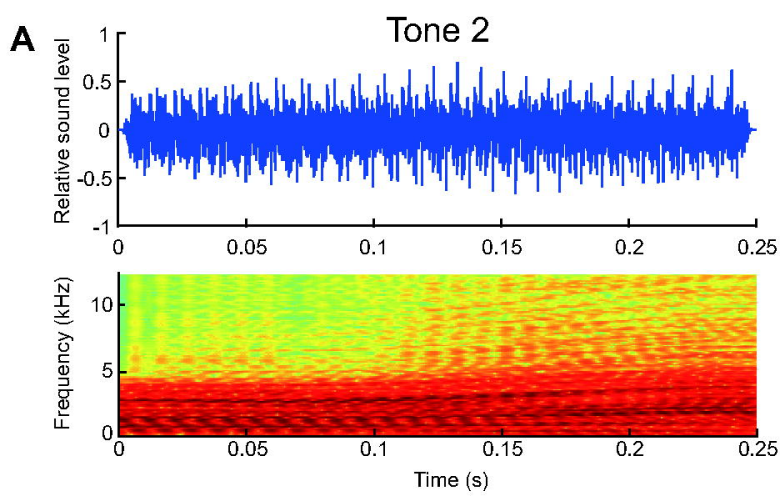

$\mathbf{B}$

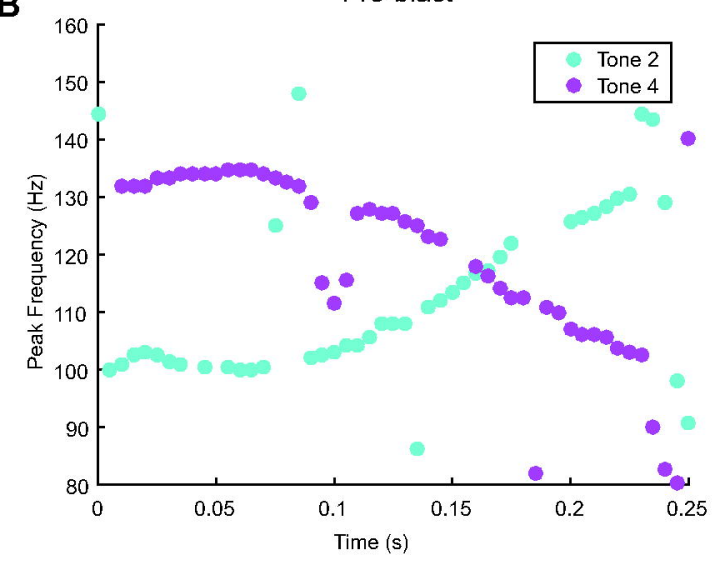

Post-blast (day 10)

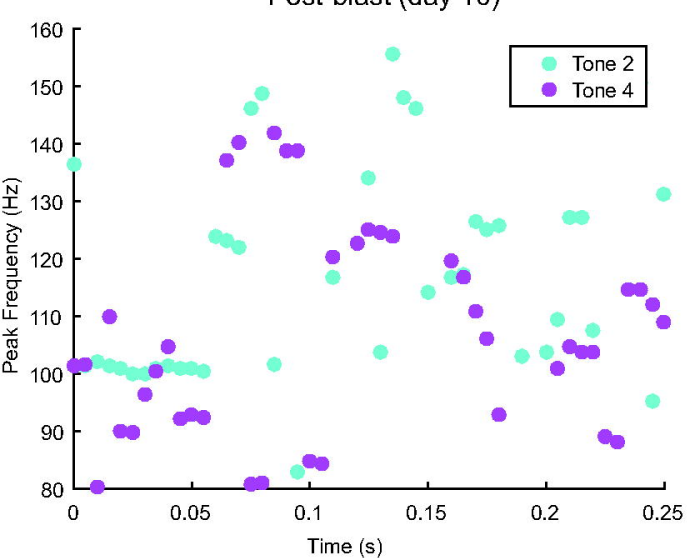

C
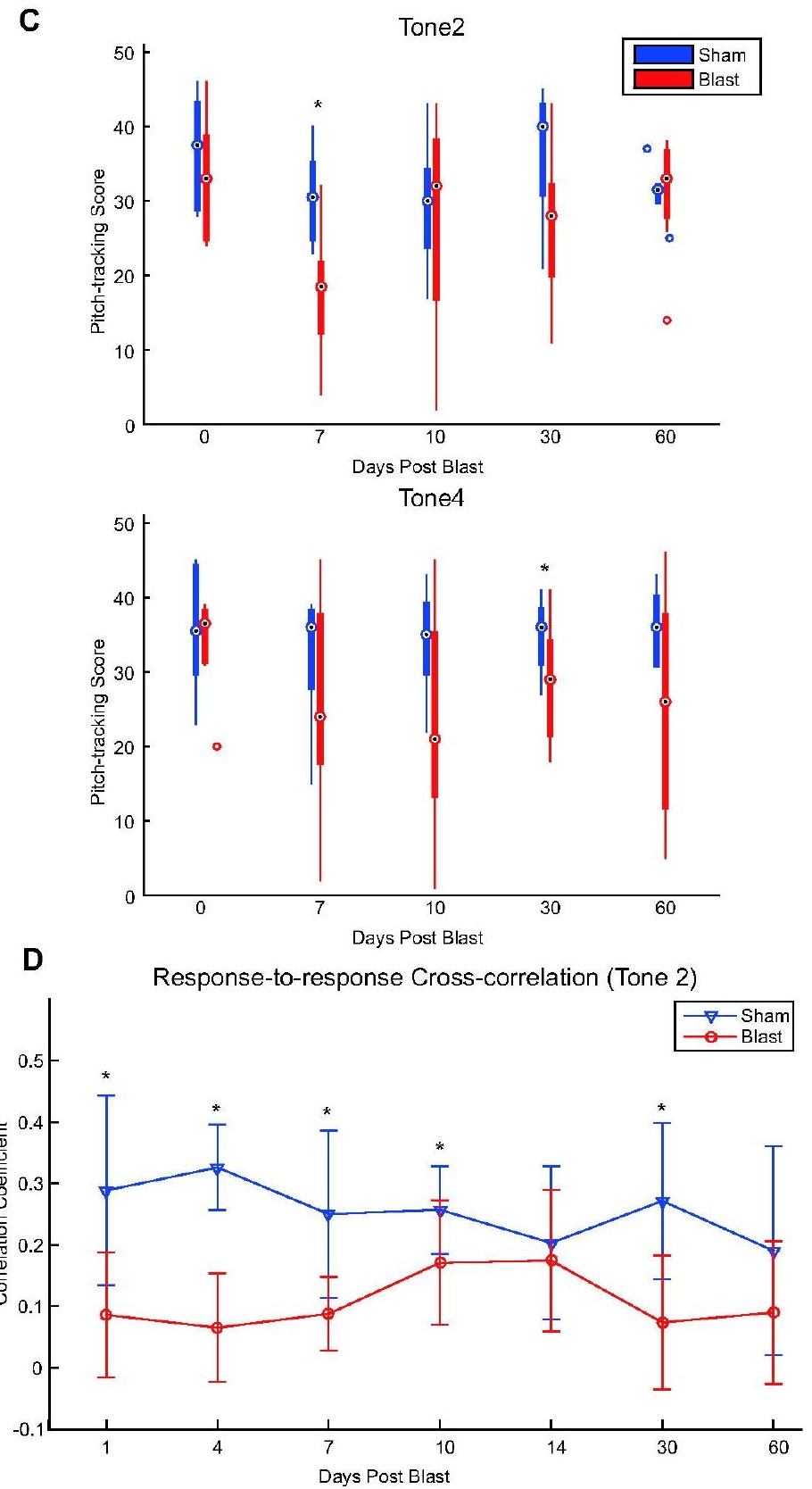
bioRxiv preprint doi: https://doi.org/10.1101/2020.11.06.371591; this version posted July 18,2021. The copyright holder for this preprint (which was not certified by peer review) is the author/funder, who has granted bioRxiv a license to display the preprint in perpetuity. It is made available under aCC-BY-NC-ND 4.0 International license.

\section{IRN Iteration Pitch-tracking (Tone 2)}

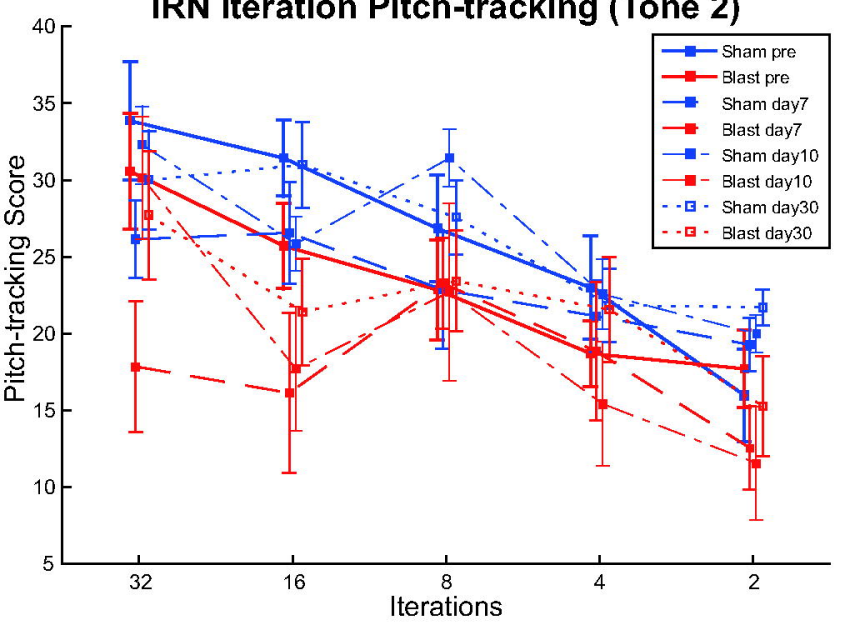

